NASA Contractor Report 194981

$$
\begin{gathered}
41.4 \\
23057 \\
41
\end{gathered}
$$

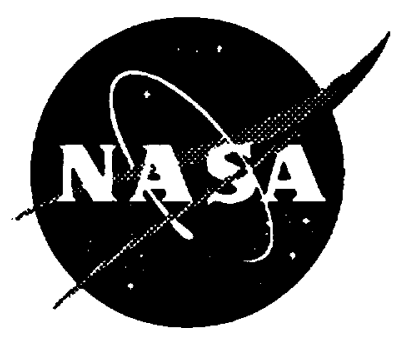

\title{
Failure Analysis of Woven and Braided Fabric Reinforced Composites
}

Rajiv A. Naik

Analytical Services \& Materials Inc., Hampton, Virginia

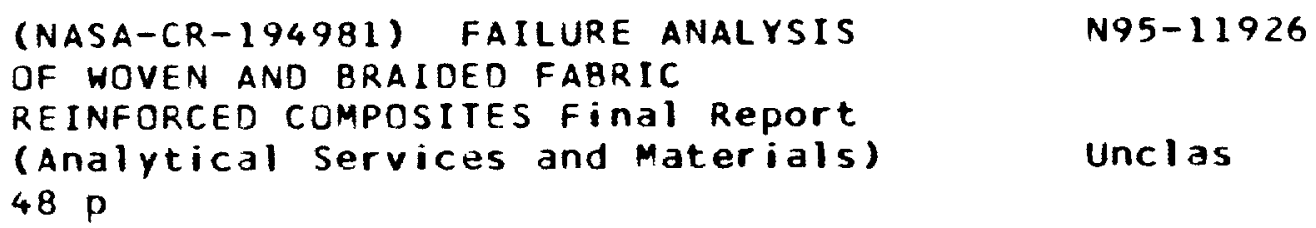

Contract NAS1-19708

September 1994

National Aeronautics and

Space Administration

Langley Research Center

Hampton, Virginia 23681-0001 



\title{
FAILURE ANALYSIS OF WOVEN AND BRAIDED FABRIC REINFORCED COMPOSITES
}

\author{
Rajiv A. Naik \\ Analytical Services \& Materials, Inc.
}

\begin{abstract}
A general purpose micromechanics analysis that discretely models the yarn architecture within the textile repeating unit cell, was developed to predict overall, three dimensional, thermal and mechanical properties, damage initiation and progression, and strength. This analytical technique was implemented in a user-friendly, personal computer-based, menudriven code called Textile Composite Analysis for Design (TEXCAD). TEXCAD was used to analyze plain weave and 2×2,2-D triaxial braided composites. The calculated tension, compression, and shear strengths correlated well with available test data for both woven and braided composites. Parametric studies were performed on both woven and braided architectures to investigate the effects of parameters such as yarn size, yarn spacing, yarn crimp, braid angle, and overall fiber volume fraction on the strength properties of the textile composite.
\end{abstract}

Key Words: textile composites, modeling, plain weave, strength, triaxial braid, yarn, crimp, design, thermal, stiffness, damage. 


\section{INTRODUCTION}

Composite materials reinforced with woven and braided fabric preforms are being considered for potential structural applications in the aircraft and automotive industries. Fabric-reinforced 'textile' composites potentially have better out-of-plane stiffness, strength, and, toughness properties than tape laminates. They are also amenable to automated and efficient manufacturing techniques. However, the architecture of a textile composite is complex and, therefore, the parameters controlling its strength properties are numerous. This necessitates the development of analytical models to predict the failure modes and strength properties of textile composites. The present study focuses on the analysis of woven and braided textile composites.

\section{Fabric Architecture}

A two-dimensional (2-D) plain weave composite laminate is one of the simplest textile composites and it consists of stacked, pre-impregnated layers of woven fabric [1] which are cured and consolidated by a process similar to tape laminates. The fabric is composed of two sets of interlacing, mutually orthogonal (warp and fill) yarns (Fig. 1). Each yarn is a bundle of filaments (or fibers) and the yarn size is measured by the number of filaments in the yarn. The fabric is woven on a loom and its architecture is characterized by the interlacing pattern of the warp and fill yarns.

The periodicity of the repeating pattern in a woven (or braided) fabric can be used to isolate a small repeating unit cell (RUC) which is sufficient to describe the fabric architecture. The RUC for the plain weave is indicated in Fig. 1 by dark borders. The interlacing of the yarns in a fabric leads to yarn undulation or 'crimp'. Composite stiffness and strength properties are governed by (i) weave parameters such as weave architecture, yarn sizes, yarn spacing, and yarn crimp; (ii) laminate parameters such as stacking orientations and overall fiber volume fraction; and (iii) material parameters such as yarn and resin stiffness and strength properties. 
Braided preforms are fabricated over a cylindrical mandrel. A single layer of a 2-D braid consists of either two or three intertwined yarns. The braider yarns follow the $+\theta$ and $-\theta$ directions and usually interlace in either a $1 \times 1$ or a $2 \times 2$ pattern $[2,3]$. For example, in a $2 \times 2$ pattern a $+\theta$ braider yarn continuously passes over two $-\theta$ braider yarns and then under two $-\theta$ braider yarns and vice versa. A 2-D triaxial braid (Fig. 2) consists of axial yarns in addition to the off-axis braider yarns. The axial yarns follow the longitudinal direction and are inserted between the braider yarns.

A 2-D triaxial braided composite laminate of a certain desired thickness is formed by overbraiding layers of the desired architecture on top of each other. After the preform is removed from the mandrel, resin is introduced by a resin transfer molding process. This leads to a two dimensional material as there are no interlayer yarns through the laminate thickness. Composite stiffness and strength properties are governed by (i) braid parameters such as braid architecture, yarn sizes, yarn spacing, and yarn crimp; and (ii) material parameters such as yarn and resin stiffness and strength properties and overall fiber volume fraction.

Typical photomicrographs for a 2x2, 2-D braided laminate are shown in Fig. 3. The longitudinal section (Fig. 3(a)) along the axial yarns indicates minor crimp in these yarns. Fig. 3(b) shows a transverse section of the laminate. The lenticular cross-sectional shape of the axial yarns is evident. Also, the axial yarns do not stack on top of one another. This is due to 'nesting' between layers during the brading operation. Fig. 3(c) shows a section along the braider yarns. The degree of crimp in the braider yarns as they interlace with the other yarns is well illustrated in this section.

\section{Analytical Techniques}

A number of analytical and numerical techniques have been used to predict the stiffness properties of both woven and braided composites and a review of the linear elastic models used in the past for the prediction of overall stiffness properties was presented in Refs. [2] and [4]. However, there are only a few models that have been developed for the strength prediction of 
textile composites. Some of the earlier models for predicting nonlinear response, damage propagation and strength of woven and braided composites are highlighted below.

Ishikawa and Chou [5] developed a 2-D fiber undulation model based on classical lamination theory which considered the undulation in the fill yarn direction but neglected the undulation in the warp yarns of a woven composite. They modeled nonlinear shear response of both the fill yarns and the interstitial matrix along with the effects of transverse cracking of the warp yarns to predict the knee in the stress-strain response of woven composites. Kriz [6] used a 2-D finite element model which assumed a linear undulation path for the fill and warp yarns to study the effect of transverse cracking on the stiffness and internal stresses of a glass/epoxy plain weave composite.

Stanton and Kipp [7] developed a nonlinear constitutive model for plain weave carboncarbon composites which accounted for the differences in tension and compression response, warp-fill crossover damage and multiaxial stress interactions using a simple interaction formula along with experimental stress-strain data for all six components under tension and compression loading. Jortner [8] developed a 2-D mechanistic model which modeled the undulations of the fill yarns but neglected the undulations of the warp yarns. He used a stressaveraging scheme which accounted for the nonlinear shear response of the fill yarns and the transverse cracking of the warp yarns to analyze plain weave carbon-carbon composites.

Ko and Pastore [9] used a fabric geometry model to define the yarn orientations in a three-dimensional (3-D) braided composite. They used the yam orientations to first estimate the strength of the fabric preform and then computed composite strength using a simple rule of mixtures. Ko [10] also used the fabric geometry model together with a maximum strain energy criterion to predict yarn failures and ultimate strength of a 3-D braided composite.

Dow and Ramnath [11] modeled woven fabric composites using a simple geometry model that assumed a linear undulation path for the fill and warp yarns. They computed constituent fiber and matrix stresses from local yarn stresses which were calculated using an iso-strain assumption and predicted failure based on the average stresses in the fiber and the 
matrix along with a maximum stress criterion. Masters, Fedro and Ifju [12] used the fabric geometry model together with a simple linear yarn bending model and an iso-strain assumption to compute average fiber and matrix stresses which were used to predict local yarn failure and strength for 2-D triaxial braided composites.

Three-dimensional finite element models (FEM) have also been used for the prediction of nonlinear material properties [13] and the modeling of damage [14] of plain weave composites. The 3-D FEMs are highly computer intensive and also require considerable time and effort for model generation. Foye [15] developed homogenized replacement finite elements and analyzed sub-cells within the RUC to overcome these limitations. However, he had to manually calculate the orientations of the different yarn directions, yarn interfacial planes and volume fractions, for each element in the 3-D model. FEM is, therefore, not well suited for performing parametric studies to investigate the sensitivity of composite strength properties to fabric architecture parameters.

The earlier analysis techniques often made simplifying assumptions regarding the fabric architecture and did not account for the geometric nonlinear effects of yarn bending and yarn straightening/ wrinkling during axial tension/ compression loading. The objective of the present study was to develop a general-purpose analysis technique for the prediction of failure initiation, damage progression, and strength of 2-D woven and braided composite materials.

A general-purpose analysis technique was previously developed by Naik, et al $[2,3]$ for the prediction of overall stiffness properties of 2-D woven and braided composites. The yarn architecture was discretely modeled using sinusoidal undulations at yarn crossovers. Overall thermal and mechanical properties were calculated based on an iso-strain assumption. This earlier analysis technique will be extended to include the effects of nonlinear shear response and nonlinear material response due to the accumulation of damage in the yarns and the interstitial matrix and also the effects of yarn bending and the geometrically nonlinear effects of yarn straightening/ wrinkling during axial tension/ compression loading. 
The present analysis technique was used to calculate the overall stress-strain response, damage progression and the failure strengths for woven and braided composites. Parametric studies were also performed on the woven and braided architectures to investigate the effects of yarn size, yarn spacing, yarn crimp, braid angle, and overall fiber volume fraction on the strength properties of the textile composite.

\section{ANALYTICAL PROCEDURES}

The analysis of a fabric reinforced composite requires, first, a proper three dimensional description of the preform architecture. The geometric modeling of the preform architecture was performed, in Refs. 2 and 3, by utilizing the periodicity of the textile composite to isolate a repeating unit cell (RUC). For each yarn within the RUC the yarn centerline path was then described by assuming a flattened lenticular cross-sectional shape for the interlacing yarns (Figs. 4 and 5). This assumption was based on the lenticular yam cross-sectional shapes observed in micrographs of the composite (see Fig. 3). Details of the geometric modeling technique and its applications to various woven and braided architectures were included in Ref. 2.

Having described the fiber architecture, the three dimensional effective stiffnesses for the composite were computed by first discretizing each yarn in the RUC into yam slices and then using the material properties, spatial orientation, and volume fraction of each yarn slice in a volume averaging technique that assumed an iso-strain state within the RUC $[2,3]$.

The above stiffness averaging procedure was used in the present study at each incremental load step to calculate the overall stiffness matrix after accounting for the effects of nonlinear shear response and local damage accumulation. The effects of yarn bending and straightening/ wrinkling were accounted for by a curved beam on elastic foundation model which was used to compute the local yarn slice stresses at each incremental load step. Maximum stress/ strain criteria were used for yarn slice failure prediction. Yarn slice stiffness 
properties were reduced appropriately at each incremental step. A cracked yam bending model was used to account for the effect of cracking on the compliance of the undulating yarn. The following subsections will describe (i) the geometric and analytical models for the plain weave and the 2-D triaxial braided composites, (ii) the nonlinear shear response model, (iii) the incremental approach, (iv) the yarn bending model, (v) the failure criteria, (vi) the stiffness reduction scheme, and (vii) the cracked yarn bending model.

\section{Geometric Model for Plain Weave Composite}

The RUC for the 2-D plain weave composite is shown in Fig. 4. The sectional view in Fig. 4 (section A-A) shows the undulations of a warp yarn as it crosses over and under the fill yarns. The undulating portion of each yarn was assumed to follow a sinusoidal path.

The plain weave composite is usually specified by known quantities such as yarn spacing, yarn filament count, yarn packing density, filament diameter, and overall fiber volume fraction. These known quantities were used to determine the unknown quantities such as yarn thicknesses, yarn cross-sectional areas, yarn crimp angle and yarn undulating paths. The geometric modeling procedure used to compute these unknown quantities was described in detail in Ref. 2.

\section{Geometric Model for 2-D Triaxial Braided Composite}

The RUC used for the 2x2, 2-D triaxial braid is shown in Fig. 5. The sectional view A-A shows the undulation of a braider yarn which undulates over and under the axial yarns in the RUC. The 2-D triaxial braided composite is usually specified by known quantities such as braid angle, axial yarn spacing, yarn filament counts for the axial and braider yarns, yarn packing density, filament diameter, and overall fiber volume fraction. Like the plain weave, these known quantities were used to determine the unknown quantities such as yarn thicknesses, yarn cross-sectional areas, yarn crimp angle and yarn undulating paths which are required to discretely model each yarn within the RUC. A detailed description of the 
geometric modeling approach for the 2×2, 2-D triaxial braided composite was presented in Refs. 2 and 3.

\section{Discretization of Yarns}

Overall composite properties were determined by discretizing each of the yams within the RUC. The straight portions of each yarn path were modeled as a single yarn slice. Along an undulating portion, the yam was divided into $n$, equal, piecewise straight slices made perpendicular to its in-plane direction and normal to the $X-Y$ plane (Fig. 5). Thus, the undulating, sinusoidal yarn path was approximated by $n$ interconnected straight yarn slices.

The spatial orientation of each yarn slice was described by the in-plane angle, $\theta$, that it made with the $X$-axis (Fig. 5) and the out-of-plane angle, $\beta$, that it made with the $X-Y$ plane. For the woven architectures, the angle $\theta$ was either 0 (warp yarns) or 90 (fill yarns) degrees. For the braided composites, the angle $\theta$, for the braider yarns, was determined from a knowledge of the braid angle. The angle $\beta$, for both woven and braided architectures, was calculated, for each yarn slice, by differentiating the sine function used to describe the undulating yarn centerline path [2]. For the yarn slice that modeled the straight portions of the yarn path, $\beta=0$ was used. The interstitial matrix was represented as an isotropic material slice having orientation angles $\theta=\beta=0$.

\section{Calculation of Three-Dimensional Effective Stiffnesses and Thermal Stresses}

For the purpose of calculating overall properties, the RUC of the textile composite was treated as a spatially oriented fiber composite composed of yam slices with transversely isotropic material properties and longitudinal material axes oriented at known angles $\theta$ and $\beta$. A stress averaging technique $[2,3]$ based on an iso-strain assumption within the RUC was used to compute the overall stiffness matrix $\left[\mathrm{C}_{\text {eff }}\right]$. The effective stiffness matrix $\left[\mathrm{C}_{\text {eff }}\right]$ of the woven or braided RUC was written as a summation over all the $\mathrm{N}$ yam slices in the RUC 
(including the interstitial matrix material slice) in terms of the yarm slice stiffness matrix $\left[C^{\cdot}\right]_{m}$, transformation matrix $[T]_{m}$, and yarn slice volume fraction $V_{m}$ as $[2,3]$

$$
\left[C_{\text {eff }}\right]=\sum_{m=1}^{N}\left(V_{m}[T]_{m}^{T}\left[C^{\cdot}\right]_{m}[T]_{m}\right)
$$

The $6 \times 6$ stiffness matrix $\left[\mathrm{C}^{\prime}\right]_{\mathrm{m}}$ defines the three-dimensional stress-strain relationship for the $\mathrm{m}^{\text {th }}$ yarn slice which is assumed to be a transversely isotropic material.

The five independent material constants $\left(E_{11}, E_{22}, G_{12}, v_{12}\right.$, and $v_{23}$, subscript 1 corresponds to the axial fiber direction) that are required to define the $\left[\mathrm{C}^{\prime}\right]_{\mathrm{m}}$ matrix could be measured quantities based on impregnated yarn tests or could also be estimated by a rule of mixtures or a micromechanics analysis (e.g. Ref. 16) from constituent properties. Such an estimate would require a knowledge of fiber properties, matrix properties and the yam packing density $p_{d}$ (or yarn fiber volume fraction). The transformation matrix $[T]_{m}$ in Eq. (1) is defined in Appendix A and is used to transform the strains from the global RUC coordinates $(\mathrm{XYZ})$ to yarn slice material coordinates $(123)$. The $[\mathrm{T}]_{\mathrm{m}}^{\mathrm{T}}$ matrix is the transpose of the matrix $[\mathrm{T}]_{\mathrm{m}}$.

Thermal residual stresses in the yarn slices were calculated based on the iso-strain assumption. For the $\mathrm{m}^{\text {th }}$ yarn slice, thermal residual stresses were given by

$$
\left\{\sigma^{\mathrm{T}}\right\}_{\mathrm{m}}=\Delta \mathrm{T}\left[\mathrm{C}^{\prime}\right]_{\mathrm{m}}\left\{[\mathrm{T}]_{\mathrm{m}}\{\bar{\alpha}\}-\left\{\alpha^{\cdot}\right\}_{\mathrm{m}}\right\}
$$

where $\Delta \mathrm{T}$ is the change in temperature from the stress free state, $\left\{\alpha^{\prime}\right\}$ are the coefficients of thermal expansion (CTE) of the $\mathrm{m}^{\text {th }}$ yarn slice and $\{\bar{\alpha}\}$ are the overall CTE for the RUC given by [2] 


$$
\{\bar{\alpha}\}=\left[\mathrm{C}_{\text {eff }}\right]^{-1}\left\{\sum_{m=1}^{N}\left(v_{m}[T]_{m}^{T}\left[C^{\prime}\right]_{m}\left\{\alpha^{\prime}\right\}_{m}\right)\right\}
$$

A convergence study was performed to determine the appropriate number of yarn slices, $\mathrm{n}$, in the undulating portions of the yarns, required to yield converged values for the overall stiffnesses [ $\left.\mathrm{C}_{\text {eff }}\right]$. The computed stiffnesses for the woven and braided composites in the present study were found to be unchanged for $n \geq 12$. A value of $n=12$ was used for all the analyses in this study.

\section{Nonlinear Shear Response}

The importance of shear material nonlinearity in the analysis of fabric reinforced composites has been recognized in previous studies $[5,8,13,14]$. A three parameter equation developed by Richard and Blacklock [17] is adopted here to represent the nonlinear shear response of both the impregnated yarns and the resin. The shear stress $\tau_{12}$ is related to the shear strain $\gamma_{12}$ by [17]

$$
\tau_{12}=\frac{G_{12} \gamma_{12}}{\left[1+\left(\frac{G_{12} \gamma_{12}}{\tau_{12}^{\text {uh }}}\right)^{\mathrm{m}}\right]^{\frac{1}{m}}}
$$

where $G_{12}$ is the initial linear shear modulus, $\tau_{12}^{\text {uk }}$ is the ultimate shear strength, and $\mathrm{m}$ is a shape parameter which can be determined by a curve-fit to experimental shear stress-strain data for the matrix [18] and the unidirectional composite [19]. Equation (4) can be differentiated with respect to the shear strain to give an expression for the tangent shear modulus $\left(G_{12}\right)_{i}$ at each incremental load step i as [20] 


$$
\left(G_{12}\right)_{i}=\left.\frac{d \tau_{12}}{d \gamma_{12}}\right|_{i}=\frac{G_{12}}{\left[1+\left(\frac{G_{12}\left(\gamma_{12}\right)_{i}}{\tau_{12}^{\text {dh }}}\right)^{m}\right]^{1+\frac{1}{m}}}
$$

Equation (5) was used to compute the instantaneous shear moduli, $G_{12}$ and $G_{13}$, for each yarn slice (including the resin material slice) in the RUC during incremental loading. For the interstitial matrix material slice the octahedral shear stress and octahedral shear strain were used in Eq. (5).

\section{Incremental Approach}

The Full Newton-Raphson Method [21] was adopted in the present technique for the incremental analysis of 2-D woven and braided composites. Thus, the overall stiffness matrix for the textile RUC was computed at each incremental step. For an increment of applied stress, $\{\Delta \bar{\sigma}\}_{i}$, at the $i^{\text {th }}$ increment, the overall incremental strains, $\{\Delta \bar{\varepsilon}\}_{i}$, were calculated as

$$
\{\Delta \bar{\varepsilon}\}_{i}=\left[\mathrm{S}_{\text {eff }}\right]_{i-1}\{\Delta \bar{\sigma}\}_{i}, \quad\left[\mathrm{~S}_{\text {eff }}\right]_{i-1}=\left[\mathrm{C}_{\text {eff }}\right]_{i-1}^{-1}
$$

where $\left[\mathrm{S}_{\mathrm{eff}}\right]_{\mathrm{i}-1}$ is the instantaneous overall compliance matrix calculated at the (i-1) $)^{\text {th }}$ incremental step and $\left[\mathrm{C}_{\mathrm{eff}}\right]$ is defined in Eq. (1). The incremental stresses, $\left\{\Delta \sigma_{\mathrm{ys}}\right\}_{\mathrm{i}}$, in each yarn slice within the RUC, were calculated based on the iso-strain assumption as

$$
\left\{\Delta \sigma_{y s}\right\}_{i}=\left[C^{\prime}\right]_{i-1}[T]\{\Delta \bar{\varepsilon}\}_{i}
$$

where the $6 \times 6$ stiffness matrix $\left[C^{\prime}\right]_{i-1}$ defines the three-dimensional stress-strain relationship for the yarn slice and the transformation matrix $[T]$ is defined in Appendix A. The $\left[\mathrm{C}^{\cdot}\right]_{\mathrm{i}-1}$ 
matrix includes the effects of nonlinear shear (Eq. (5)) and also the effects of damage accumulation (described later). The incremental yarn slice stresses (Eq. (7)) were volume averaged [2, 3] after transforming to global RUC coordinates to compute the new overall stiffness matrix $\left[\mathrm{C}_{\mathrm{eff}}\right]_{\mathrm{i}}$ (see Eq. (1)).

The cumulative stresses in each yarn slice were used together with appropriate failure criteria (described later) to predict failure at each incremental step. Some of the strains and stresses in the undulating portions of a yarn were calculated using a yarn bending model (described later) which accounted for the nonlinear effects of yarn straightening/ wrinkling. Failure within the yarn slices in the model was accounted for in two different ways. A stiffness reduction scheme (described later), based on the mode of predicted failure, was used to account for yarn slice failure throughout the RUC. For yarn slices, in the undulating portion of the yarn, that failed in a transverse normal or longitudinal shear failure mode, failure was also accounted for by using a cracked yarn bending model (described later) to account for the change in yarn compliance.

\section{Yarn Bending Model}

A curved beam on elastic foundation model was used in the present study to represent the bending and straightening/ wrinkling behavior of the undulating portion of the yarns within the RUC. The Euler-Bernoulli beam theory was assumed to be applicable to the impregnated yarn. The constraint provided by the surrounding interstitial matrix and yam material was represented by an elastic foundation. Using the coordinate system shown in Fig. 6, the initial sinusoidal undulation, $\mathrm{z}_{0}$, of the yarn can be described as:

$$
\mathrm{z}_{\mathrm{o}}=\mathrm{A}_{\mathrm{o}} \sin (\beta \mathrm{x}), \quad \beta=\frac{\pi}{\mathrm{L}_{\mathrm{u}}}
$$

where $L_{u}$ is the yarn undulating length and $A_{0}$ is the amplitude of the sine wave used to describe the yarn undulation. Note that the x-axis is oriented in the direction of the yarn path. 
The deformation, $\mathrm{z}$, of the yarn upon application of a force $\mathrm{F}$ (tension or compression) is assumed to be of the form [22]:

$$
z=A_{1} \sin (\beta x)
$$

where $A_{1}$ is the amplitude of the yarn deformation. Thus, the deformed shape, $z_{1}$, of the yarn is given by

$$
z_{1}=\left(A_{0}+A_{1}\right) \sin (\beta x)
$$

The principle of minimum potential energy was used to derive an expression for the unknown coefficient $A_{1}$. The potential energy for the curved beam on elastic foundation (Fig. 6) can be written based on the analysis of Lee and Harris [23]:

$\Pi=-\frac{1}{2}\left(\frac{F^{2} L_{u}}{A E_{11}}\right)+\frac{1}{4}\left(F L_{u} \beta^{2} A_{1}\left(A_{1}+2 A_{0}\right)\right)+\frac{1}{48}\left(E_{11} A t^{2} A_{1}^{2} \beta^{4} L_{u}\right)+U_{F}$

where the first two terms represent the potential energy due to the extensional deformation in the yarn and the work done by the applied force F, respectively, the third term represents the bending energy of the yarn, and $U_{F}$ represents the potential energy of the elastic foundation (derived later). $E_{11}$ is the axial modulus of the impregnated yarn material, and $A$ and $t$ are yarn cross-sectional area and thickness, respectively.

The elastic foundation was assumed to be an array of linear springs which carried only tension-compression forces. The shear stiffness of the foundation was assumed to be negligible, thus, allowing for local relative motion between interlacing yarns. Such a relative motion would occur in the presence of a cross-over damage mechanism which was observed and modeled by Stanton and Kipp [7].

The through-thickness modulus, $\mathrm{E}_{\mathrm{zz}}$, of the textile composite, calculated using the stress-averaging scheme described earlier, was used in the derivation of the spring constant for 
the foundation which was assumed to extend through one layer above and below the layer being modeled. Thus, for a layer with a thickness of $\left(2 A_{0}+t\right)$, the foundation was assumed to have a total length, $H_{k}$, (see Fig. 6) of $H_{k}=3\left(2 A_{o}+t\right)$. Due to the sinusoidal shape of the undulating yarn, the foundation spring constant, $K$, was a function of $x$ and was derived, using the procedure developed by Lee and Harris [23], as

$$
K=\frac{2 A a E_{z z}}{t A_{0}\left(a^{2}-\sin ^{2}(\beta x)\right)}, \quad a=3+\frac{t}{A_{0}}
$$

The potential energy, $U_{F}$, of the foundation in Eq. (11) can then be derived as

$$
U_{F}=\frac{1}{2} \int_{-L_{0} / 2}^{L_{0} / 2} K z^{2} d x
$$

Using Egs. (9), (11)-(13) and the mininmum potential energy theorem, an expression for the unknown coefficient, $A_{1}$, (Eq. (9)) can be derived as

$$
A_{1}=\frac{-F \beta^{2} A_{0}}{E_{11} I \beta^{4}+F \beta^{2}+k}, \quad I=\frac{A t^{2}}{12}, \quad k=\frac{4 E_{z z} A a}{t A_{0}}\left(\frac{a}{\sqrt{a^{2}-1}}-1\right)
$$

Only the yarn strains in the $x-z$ plane (Fig. 6) were calculated from the above model. The other components of the strains were available from the iso-strain assumption discussed earlier. The strains in the $x-z$ plane were expressed as [23],

$$
\begin{aligned}
& \varepsilon_{x}=-\frac{1}{4}\left(\beta^{2} A_{1}\left(A_{1}+2 A_{0}\right)\right)[1+\cos (2 \beta x)]+\varepsilon_{i-0} \\
& \varepsilon_{2}=-v_{13} \varepsilon_{i-4}, \quad \varepsilon_{i-4}=\frac{F}{E_{11} A}
\end{aligned}
$$


where $v_{13}$ is the Poisson's ratio for the impregnated yarn material ( 1 - fiber direction), and $\varepsilon_{i-1}$ is the strain, in the $x$-direction, available from the iso-strain assumption. The axial stress, $\sigma_{x}$, in the impregnated yarn was given by, $\sigma_{x}=(F / A)$ and the shear stress, $\tau_{x z}$, was given by $\tau_{x z}=(Q / A)$, where the transverse shear force $Q$ was derived by considering the equilibrium of the curved beam on elastic foundation model as [22]

$$
Q=F \frac{d z_{1}}{d x}-\frac{d M}{d x}, \quad M=E_{11} I \frac{d^{2} z}{d x^{2}}
$$

The other components of stress in the undulating yarn were calculated, for each yarn slice, based on the iso-strain assumption. The above strains and stresses were calculated at the centroid of each yarn slice along the yarn undulating portion and used in failure criteria (described later) to predict the onset and growth of damage in the undulating portion of each yarn. A special cracked yarn bending model (described later) was used to account for the effect of yarn cracking on the deformation of the undulating portion of the yarn.

The geometrically nonlinear effects of yarn straightening/ wrinkling were accounted for in the yarn bending model by updating the yarn undulation length, $L_{u}$, and the amplitude, $A_{o}$, of the sinusoidal yarn undulation at each incremental step, $i$, as

$$
\begin{aligned}
& \left(A_{0}\right)_{i+1}=\left(A_{0}\right)_{i}+\left(A_{1}\right)_{i} \\
& \left(L_{u}\right)_{i+1}=\left(L_{u}\right)_{i}\left\{1+\left(\varepsilon_{i-s}\right)_{i}\right\}
\end{aligned}
$$

The above yarn bending model was applied, at each incremental step, to each undulating portion of each yarn within the textile RUC.

\section{Failure Criteria}

Fiber dominated failure of the impregnated yarn slices was predicted using a maximum strain criterion for both tension and compression axial yarn stresses $\left(\sigma_{11}, 1\right.$ - fiber direction). 
Matrix dominated failures within the yarn slices were predicted using maximum stress criteria for each matrix dominated failure mode, such as, transverse tension $\left(\sigma_{22}, \sigma_{33}\right)$, transverse shear $\left(\tau_{23}\right)$, and longitudinal shear $\left(\tau_{12}, \tau_{13}\right)$.

Matrix material slice failure was predicted using two different failure criteria. A maximum principal stress criterion was used in the absence of applied shear stresses, while, a maximum octahedral shear stress criterion was used in the presence of shear stresses.

Composite failure was predicted when (i) axial yarn failure was detected anywhere in the RUC; or (ii) all yarn slices failed in the same failure mode (e.g. transverse tension or inplane shear) and failure was detected in the interstitial matrix material slice.

\section{Stiffness Reduction}

The stiffness reduction scheme used by Blackketter, et al [14], for the damage modeling of plain weave composites, was adopted in the present analysis technique. The stiffnesses of each impregnated yarn slice in the model were reduced based on the predicted mode of failure. For transverse tension failure, the corresponding Young's modulus was reduced by $99 \%$ along with the reduction of shear moduli $G_{12}$ and $G_{13}$ by $80 \%$. For transverse shear failure, under the action of $\tau_{23}$ stresses, the transverse moduli $E_{22}$ and $E_{33}$,

and the shear modulus $G_{23}$ were reduced by $99 \%$ while the longitudinal shear moduli $G_{12}$ and $G_{13}$ were reduced by $80 \%$. For longitudinal shear failures, under the action of $\tau_{12}$ stresses, $E_{22}$ and $G_{12}$ were reduced by $99 \%$. For longitudinal shear failures, under the action of $\tau_{13}$ stresses, $E_{33}$ and $G_{13}$ were reduced by $99 \%$.

For the matrix material slice, all stiffnesses were reduced by $99 \%$ when matrix failure was predicted.

\section{Cracked Yarn Bending Model}

A cracked beam on elastic foundation model was used to model yarn splitting failure in the undulating regions. The yarn splitting, which could result due to normal, $\sigma_{33}$, or 
longitudinal shear, $\tau_{13}$, stresses, was modeled as a yarn centerline crack of length, $L_{c}$, as shown in Fig. 7. The length $L_{c}$ was determined based on the number of yarn slices that had failed by exceeding either the $\sigma_{33}$ or the $\tau_{13}$ stress allowables in the yarn undulating region. The deformation of the cracked yarn model was assumed to be of the same form (Eq. (9)) as the yarn bending model, described earlier. The bending energy, $U_{b}$, of the cracked yarn was derived by representing the cracked region as two beams of thickness ( $t / 2)$ and was given by

$$
\begin{aligned}
& \mathrm{U}_{b}=\frac{\alpha_{c}}{48}\left(\mathrm{E}_{11} A \mathrm{t}^{2} \mathrm{~A}_{1}^{2} \beta^{4} \mathrm{~L}_{\mathrm{u}}\right) \\
& \alpha_{c}=1+\left(\frac{3}{4}\right)\left(\frac{\sin \left(\pi\left(\mathrm{L}_{\mathrm{c}} / \mathrm{L}_{\mathrm{u}}\right)\right)}{\pi}-\frac{\mathrm{L}_{\mathrm{c}}}{\mathrm{L}_{\mathrm{u}}}\right)
\end{aligned}
$$

The other energy terms in Eq. (11) remained unchanged for the cracked beam model. Using the minimum potential energy theorem, the unknown coefficient, $A_{1}$, for the cracked yarn model was given by

$$
A_{1}=\frac{-F \beta^{2} A_{0}}{\alpha_{c} E_{11} I \beta^{4}+F \beta^{2}+k}
$$

As in the yarn bending model, only the yarn strains in the $x-z$ plane were calculated (using Eq. (15) ) from the above model. The other components of the strains were available from the iso-strain assumption discussed earlier.

\section{RESULTS AND DISCUSSION}

The above analytical technique, for predicting textile composite stiffness and strength properties, was implemented in a user-friendly, menu-driven, personal computer-based code called Textile Composite Analysis for Design (TEXCAD). Besides the strength predictions, TEXCAD also predicts overall in-plane stress-strain response and the sequence of the yarn 
slice failures and failure modes for any uniaxial or multiaxial applied stress states. In the present paper, TEXCAD was used to analyze 2-D plain weave and 2x2, 2-D triaxial braided composites. The calculated in-plane stress-strain response and strengths were correlated with available test data. Parametric studies were also performed to study the effects of various fabric parameters on the strength properties.

All the analyses in the present study were done for textile composites which consisted of yarns made of Hercules AS4 graphite fibers impregnated with Hercules 3501-6 epoxy matrix. A yarn fiber packing density, $p_{d}$, of 0.70 was measured, in Ref. 14, using image analysis, for plain weave composites. For the braided composites $p_{d}=0.75$ was assumed for the impregnated yarns based on the analysis in Ref. 15. A fiber diameter, $d_{f}$, of $0.007 \mathrm{~mm}$ was used in all calculations.

The mechanical and thermal properties used for the impregnated yarns $\left(V_{f}=70 \%\right.$ and 75\%) and the resin are given in Table 1. The CTE's for the impregnated yarns were calculated in Ref. 2 using a micromechanics analysis based on an Airy's stress function approach for a square fiber packing $[16,24]$. The nonlinear shear shape parameter, $m$, (Eq. (4)) was determined by a curve-fit to experimental shear stress-strain data for the matrix [18] and the unidirectional composite [19] and is also given in Table 1.

Since the strength properties of the impregnated yarns are not usually available, the strain/ stress allowables for the impregnated yarns were estimated based on the available unidirectional composite strengths $\left(V_{f}=60 \%\right)$ and the calculated fiber-matrix stresses from a micromechanics analysis $[16,24]$ for a $V_{f}=75 \%$. Thus, the transverse strength of the unidirectional composite $\left(V_{f}=60 \%\right)$ was reduced by $50 \%$ to get the transverse strength of the impregnated yarns $\left(V_{f}=75 \%\right)$ to account for the 50\% higher fiber-matrix normal stresses for the higher fiber volume fraction. Similarly, the shear strength of the impregnated yarns was estimated by reducing the unidirectional composite $\left(V_{f}=60 \%\right)$ shear strength by $20 \%$ to account for the $20 \%$ higher shear stresses at the fiber-matrix interface for $V_{f}=75 \%$. The axial (tension and compression) ultimate strains for the unidirectional composite were used 
without modification for the impregnated yarns. The ultimate strain and stress properties used in the present study for the impregnated yarns and the resin are given in Table 2.

All the strength calculations in the present study were performed by accounting for the effects of thermal residual stresses which were calculated (Eq. (2)) for a temperature change of $150^{\circ} \mathrm{C}$ from the stress free temperature.

\section{Plain Weave Composites}

The tension, compression, and shear strengths for plain weave composites calculated using TEXCAD (the present analysis) are shown in Table 3. The calculated results correlated well with test data. The architecture was not fully specified for the plain weave composites in Ref. 14. Therefore, a yarn spacing of $2.22 \mathrm{~mm}$ and a yarn size of $3 \mathrm{k}$ (k - one thousand filaments) was assumed for the analysis.

Table 3 also includes results for plain weave composites with different overall fiber volume fractions and yarn characteristics (size and spacing). A 3.3\% increase in the overall fiber volume fraction (from $60 \%$ to $62 \%$ ) did not change the shear strength but led to a decrease in the tension and compression strengths by $7.7 \%$ and $3 \%$, respectively. This decrease in strength may be attributed to the increase in the yarn crimp angle from $8.9^{\circ}$ to $10.7^{\circ}$ for the higher fiber volume fraction. The tension and compression strengths for the composite with the $12 \mathrm{k}$ yarns were lower by $23 \%$ and $18 \%$, respectively, than the composite with $3 \mathrm{k}$ yarns and a $60 \%$ fiber volume fraction. The larger yarn size led to a crimp angle of $10.2^{\circ}$, thus, accounting for some of the drop in the strength. It also led to an increase in the rate of damage accumulation during tension and compression loading, thus, leading to the predicted trend.

The stress-strain response under tension and compression loading is shown in Fig. 8 and under in-plane shear loading is shown in Figs. 9 and 10. The predicted knee in the tension stress-strain response at about $80 \mathrm{MPa}$ (Fig. 8) correlated well with the test data [14]. This knee resulted from the transverse tension failure of the yarns that were oriented 
perpendicular to the loading direction. The knee behavior was not predicted under compression loading (Fig. 8) because the transverse compression strength of the yarns was much higher than their tension strength (Table 2). Longitudinal shear failure in the undulating regions of the longitudinally loaded yarns was predicted under both tension and compression loading during the upper half of the stress-strain curve.

Under shear loading, longitudinal shear failure initiated in the yarn slices at around $85 \mathrm{MPa}$. Damage accumulation in the yarn slices contributed to the initial part of the nonlinear response (Figs. 9 and 10). This was consistent with the analytical predictions in Ref. 14. The final part of the stress-strain response, after all the yarns had failed, corresponded to the nonlinear shear response of the matrix material slice. Final composite failure was predicted when the interstitial matrix failed. The experimental $[14,25]$ and the predicted shear stress-strain curves (Figs. 9 and 10) were in reasonably good agreement.

\section{2x2, 2-D Triaxial Braided Composites}

The three different triaxial braided composites tested in Refs. 12 and 26 were analyzed using the present TEXCAD analysis. The yarn architecture parameters such as braid angle, braider and axial yarn sizes, axial yarn spacing and overall composite volume fraction for the three architectures (A1, B1, B2) are given in Table 4. These parameters along with a yarn packing density of 0.75 and a fiber diameter of $0.007 \mathrm{~mm}$ were used as input to TEXCAD for calculating the results in Table 5. The specimens in Ref. 12 were made with AS4 graphite fiber yarns and Shell 1895 epoxy resin. It was assumed that the 1895 epoxy had the same material properties as the 3501-6 resin (Tables 1 and 2). Thus, the material properties for the impregnated yarns and the resin in Tables 1 and 2 were used in the present analysis of 2-D triaxial braids.

Correlations of the computed strengths (Table 5) with test data $[12,26]$ were reasonably good for all the three architectures. Under longitudinal tension loading, transverse failures were predicted in the braider yarns at about $75 \mathrm{MPa}$ followed by matrix failure at 
around $300 \mathrm{MPa}$. Final composite failure occurred when the axial yarns failed in the axial tension failure mode. The longitudinal tension strength prediction for the $\mathrm{Bl}$ architecture correlated well with the test data, however, the predictions for the A1 and B2 architectures were higher by $17 \%$ and $28 \%$, respectively. A parametric study was performed to investigate the effects of braid architecture parameters on tension strength in order to understand (i) the poor correlation between predictions and test data for the A1 and B2 architectures; and (ii) the experimentally observed large difference in the tension strengths for the largely similar B1 and B2 architectures (Tables 4 and 5).

The effects of axial yarn spacing, overall fiber volume fraction, braid angle and axial yarn crimp on the longitudinal tension strength were investigated as a part of this parametric study. Axial yarn spacing is a function of the mandrel diameter and the number of axial yarn carriers used during the braiding operation. Inadvertent use of a different mandrel diameter can result in an axial yarn spacing that is different from what was intended. The overall fiber volume fraction for a textile composite, measured after fabrication, can often differ, by a few percent, from the specified fiber content. Furthermore, variations may occur in the fiber volume fraction from one composite plate to another. Variations in the braid angle are also possible during fabrication. Although the axial yarns are intended to remain straight after fabrication, axial yarn crimp (or waviness) can result from (i) the braiding operation if the tension in the axial yarns is inadequate or (ii) the interpenetration of the braided layers during compaction of the composite. Note that, the predictions in Table 5 were obtained by assuming straight axial yarns with no crimp.

The results of the parametric study are included in Figs. 11-14. The test data [12, 27] available for the three different architectures is also include in the figures. The longitudinal tension strength remained unchanged with the axial yarn spacing (Fig. 11) and this was consistent with the trend in the test data. The tension strength increased with increasing overall fiber volume fraction (Fig. 12) and this trend was also in agreement with the test data. The strength was not very sensitive to changes in volume fraction and only increased by $1 \%$ 
for a percent change in the volume fraction. The strength decreased with an increase in the braid angle (Fig. 13). As with the volume fraction, the strength was not very sensitive to changes in the braid angle and only decreased by $1.5 \%$ for a percent change in the braid angle. As expected, the tension strength decreased with increasing axial yam crimp angle (Fig. 14). A crimp angle of only 5 degrees led to a strength reduction of about $5.5 \%$ and a crimp angle of 10 degrees led to an average reduction in strength of about $15 \%$.

Based on the micrographs in Fig. 3, some crimp in the axial yarns is apparent in the longitudinal cross-sectional view. This axial yarn crimp will lead to (i) reduced longitudinal tension strengths than predicted by a model that assumes straight axial yarns and (ii) a large scatter in the data (as observed for the B1 and B2 architectures) for specimens from different panels or batches. The range of tension strength variability for axial yarn crimp variations from 0 to 12 degrees has been shown in Fig. 15 for the three different architectures. The measured tension strengths for the $\mathrm{A} 1, \mathrm{~B} 1$, and $\mathrm{B} 2$ architectures were found to be within the range of tension strengths predicted after accounting for axial yarn crimp.

The predicted transverse tension and compression strengths (Table 5) follow the general trends in the data. Under transverse tension loading, damage initiated by the transverse tension failure of the axial yarns at about $60 \mathrm{MPa}$. Transverse tension failure in the braider yarns was predicted just before final composite failure which occurred when the matrix material slice failed. The effects of yarn size on the transverse strength of the yarns and specimen edge effects were not accounted for in the prediction of transverse tension strength.

Under longitudinal compression loading, compression failure of the axial yarns in the undulating region led to the final failure of the composite. The longitudinal compression strength of braided composites is expected to exhibit more variability than laminated composites due to the inhomogeniety of the material form and the effects of axial yarn crimp. The predictions for both the transverse tension strength and the longitudinal compression strength (Table 5) using the TEXCAD program are, therefore, expected to be merely good engineering estimates of strength. 


\section{SUMMARY}

A general purpose micromechanics analysis that discretely models the yarn architecture within the textile repeating unit cell, was developed to predict overall, three dimensional, thermal and mechanical properties, damage initiation and progression, and strength. This analytical technique was implemented in a user-friendly, personal computer-based, windows compatible code called Textile Composite Analysis for Design (TEXCAD). TEXCAD was used to analyze plain weave and 2×2,2-D triaxial braided composites.

Based on the results for the plain weave composite, a $3.3 \%$ increase in the overall fiber volume fraction did not change the shear strength but led to a decrease in the tension and compression strengths by $7.7 \%$ and $3 \%$, respectively. A larger yarn size led to a larger crimp angle and an increase in the rate of damage accumulation during tension and compression loading resulting in lower strengths. The knee behavior under tension loading was well predicted by the TEXCAD analysis and correlated well with the test data. Under shear loading, damage accumulation in the yarn slices and the nonlinear shear behavior of the matrix contributed to the nonlinear response. The experimental and the predicted shear stress-strain curves were in reasonably good agreement.

Results of the parametric study for the 2×2,2-D braided composite indicated that the longitudinal tension strength remained unchanged with the axial yarn spacing and it increased with increasing overall fiber volume fraction and both these trends were consistent with the test data. The strength decreased with increasing braid angle and increasing axial yarn crimp angle. A crimp angle of only 5 degrees led to a strength reduction of about $5.5 \%$ and a crimp angle of 10 degrees led to an average reduction in strength of about $15 \%$.

The present TEXCAD analysis provides a useful tool for the prediction of thermoelastic constants, damage initiation and growth, and strength for a wide range of textile composite architectures. It also provides a means to conduct sensitivity studies for the numerous parameters that can affect the stiffness and strength properties of textile composites. Finally, it has the potential for being implemented as a material constitutive model in structural 
stress analysis codes, as a substitute for the currently used phenomenological or curve-fit constitutive models, thus, providing the capability of structural analysis for textile composite structures.

\section{ACKNOWLEDGMENT}

This work was supported by NASA under Contract Nos. NAS1-19399 and NAS119708. The author wishes to thank Dr. John E. Masters for providing the micrographs in Figure 3. 


\section{APPENDIX A}

The transformation matrix $[\mathrm{T}]_{\mathfrak{l n}}$ in Eq. (1) is defined as $[2,3]$

$$
[T]_{m}=\left[\begin{array}{cccccc}
a_{11}^{2} & a_{12}^{2} & a_{13}^{2} & a_{12} a_{13} & a_{11} a_{13} & a_{11} a_{12} \\
a_{21}^{2} & a_{22}^{2} & a_{23}^{2} & a_{22} a_{23} & a_{23} a_{21} & a_{21} a_{22} \\
a_{31}^{2} & a_{32}^{2} & a_{33}^{2} & a_{32} a_{33} & a_{33} a_{31} & a_{31} a_{32} \\
2 a_{21} a_{31} & 2 a_{32} a_{22} & 2 a_{23} a_{33} & \left(a_{22} a_{33}+a_{23} a_{32}\right) & \left(a_{23} a_{31}+a_{21} a_{33}\right) & \left(a_{21} a_{32}+a_{22} a_{31}\right) \\
2 a_{11} a_{31} & 2 a_{12} a_{32} & 2 a_{13} a_{33} & \left(a_{32} a_{13}+a_{33} a_{12}\right) & \left(a_{11} a_{33}+a_{13} a_{31}\right) & \left(a_{31} a_{12}+a_{32} a_{11}\right) \\
2 a_{11} a_{21} & 2 a_{12} a_{22} & 2 a_{13} a_{23} & \left(a_{12} a_{23}+a_{13} a_{22}\right) & \left(a_{13} a_{21}+a_{11} a_{23}\right) & \left(a_{11} a_{22}+a_{12} a_{21}\right)
\end{array}\right]
$$

where $a_{i j}(i=1-3, j=1-3)$ are the direction cosines between the yarn slice material coordinate axes (123) and the global RUC axes (XYZ) (see Fig. 5). For a yarn slice with its longitudinal material axis (1-axis) oriented at angles $\theta$ and $\beta$ with respect to the global RUC coordinates, the $3 \times 3,\left[a_{i j}\right]$ matrix $(i=1-3, j=1-3)$ is given by

$$
\left[a_{i j}\right]=\left[\begin{array}{ccc}
\cos (\theta) \cos (\beta) & \sin (\theta) \cos (\beta) & \sin (\beta) \\
-\sin (\theta) & \cos (\theta) & 0 \\
-\cos (\theta) \sin (\beta) & -\sin (\theta) \sin (\beta) & \cos (\beta)
\end{array}\right]
$$

Equation (A2) was derived by assuming that the 2-axis (i.e. the in-plane transverse direction, see Fig. 5) of the yarn slice was always perpendicular to the global $Z$-axis for any $\theta$ or $\beta$ rotation of the yarn slice 1-axis (i.e. the axial fiber direction). This merely simplified the definition of the direction cosines without compromising the generality of the approach. 


\section{REFERENCES}

1. Bailey, J. A.: "Woven Fabric Aerospace Structures," Handbook of Composites, Vol. 2 Structures and Design, C. T. Herakovich and Y. M. Tarnopol'skii, Eds., 1989, pp. 354391, Elsevier Science Publishers B. V.

2. Naik, R. A.: "Analysis of Woven and Braided Fabric Reinforced Composites", NASA Contractor Report 194930, June 1994, National Aeronautics and Space Administration, Hampton, Virginia. Also presented at the ASTM 12th Symposium on Composite Materials: Testing and Design, May 16-17, 1994, Montreal, Canada.

3. Naik, R. A., Ifju, P. G. and Masters, J. E.: "Effect of Fiber Architecture Parameters on Deformation Fields and Elastic Moduli of 2-D Braided Composites", Journal of Composite Materials, Vol. 28, No. 7, 1994, pp. 656-681.

4. Raju, I. S., Foye, R. L. and Avva, V. S.: "A Review of Analytical Methods for Fabric and Textile Composites," Proceedings of Indo-US Workshop on Composite Materials for Aerospace Applications, Bangalore, India, July 23-27, 1990, available as Composite Structures, Testing, Analysis and Design, J. N. Reddy and A. V. Krishna Murty, Eds., 1992, pp. 274-293, Narosa Publishing House, New Delhi, India.

5. Ishikawa, T. and Chou, T-W.: "Nonlinear Behavior of Woven Fabric Composites," Journal of Composite Materials, Vol. 17, September 1983, pp. 399-413.

6. Kriz, R. D.: "Influence of Damage on Mechanical Properties of Woven Composites at Low Temperatures," Journal of Composites Technology and Research, Vol. 7, No. 2, Summer 1985, pp. 55-58.

7. Stanton, E. L. and Kipp, T. E.: "Nonlinear Mechanics of Two-Dimensional CarbonCarbon Composite Structures and Materials," AIAA Journal, Vol. 23, No. 8, August 1985, pp. 1278-1284.

8. Jortner, J.: "A Model for Nonlinear Stress-Strain Behavior of 2D Composites with Brittle Matrices and Wavy Yarns," Advances in Composite Materials and Structures, AMD-Vol. 82, S. S. Wang and Y. D. S. Rajapakse, Eds., Proceedings of the ASME Winter Annual Meeting, Anaheim, California, Dec. 10-12, 1986, The American Society of Mechanical Engineers, New York, pp. 135-146.

9. Ko, F. K. and Pastore, C. M.: "Structure and Properties of an Integrated 3-D Fabric for Structural Composites, "Recent Advances in Composites in the United States and Japan, ASTM STP 864, J. R. Vinson and M. Taya, Eds., American Society for Testing and Materials, Philadelphia, 1985, pp. 428-439. 
10. Ko, F. K.: "Three-Dimensional Fabrics for Composites," Composite Materials Series, 3, Textile Structural Composites, T-W. Chou and F. K. Ko, Eds., Elsevier, New York, 1989, pp. 129-171.

11. Dow, N. F. and Ramnath, V.: "Analysis of Woven Fabrics for Reinforced Composite Materials," NASA CR-178275, April 1987, National Aeronautics and Space Administration, Hampton, Virginia.

12. Masters, J. E, Fedro, M. J. and Ifju, P. G.: "An Experimental and Analytical Characterization of Three Triaxially Braided Textile Composites," Proceedings of the Third NASA Advanced Composites Technology Conference, NASA CP 3178, Part 1, Vol. I, 1992, pp. 263-286.

13. Bhandarkar, S., Dasgupta, A., Pecht, M. and Barker, D.: "Non-Linear ThermoMechanical Properties of Fabric Reinforced Printed Wiring Boards," Proceedings of the 5th International SAMPE Electronics Conference, Vol. 5, Los Angeles, California, Jun. 18-20, 1991, Society for the Advancement of Material and Process Engineering, pp. 248257.

14. Blackketter, D. M., Walrath, D. E. and Hansen, A. C.: "Modeling Damage in a Plain Weave Fabric-Reinforced Composite Material," Journal of Composites Technology and Research, JCTRER, Vol. 15, No. 2, Summer 1993, pp. 136-142.

15. Foye, R. L.: "Approximating the Stress Field Within the Unit Cell of a Fabric Reinforced Composite Using Replacement Elements," NASA CR-191422, Feb. 1993, National Aeronautics and Space Administration, Hampton, Virginia.

16. Naik, R. A.: "Micromechanical Combined Stress Analysis - MICSTRAN, A User Manual," NASA CR-189694, Oct. 1992. Program available as NASA LAR-15005, COSMIC, 1992. National Aeronautics and Space Administration, Hampton, Virginia.

17. Richard, R. M. and Blacklock, J. R.: "Finite Element Analysis of Inelastic Structures," AlAA Journal, Vol. 7, No. 3, March 1969, pp. 432-438.

18. Crane, D. A. and Adams, D. F.: "Finite Element Micromechanical Analysis of a Unidirectional Composite Including Longitudinal Shear Loading," AMMRC TR 81-7, Feb. 1981, Army Materials and Mechanics Research Center, Watertown, Massachusetts.

19. Adams, D. F. and Crane, D. A.: "Combined Loading Micromechanical Analysis of a Unidirectional Composite," Composites, Vol. 15, No. 3, July 1984, pp. 181-192.

20. Bogetti, T. A., Gillespie, J. W., Jr., Lamontia, M. A.: "The Influence of Ply Waviness with Nonlinear Shear on the Stiffness and Strength Reduction of Composite 
Laminates," AMD-Vol. 159, Mechanics of Composite Materials: Nonlinear Effects, ASME 1993, The American Society of Mechanical Engineers, New York, pp. 163-172.

21. Bathe, K. J. and Cimento, A. P.: "Some Practical Procedures for the Solution of Nonlinear Finite Element Equations," Computer Methods in Applied Mechanics and Engineering, Vol. 22, 1980, pp. 59-85.

22. Bert, C. W.: "Micromechanics of the Different Elastic Behavior of Filamentary Composites in Tension and Compression," Mechanics of Bimodulus Materials, AMDVol. 33, Dec. 1979, The American Society of Mechanical Engineers, New York, pp. 1728.

23. Lee, J-W. and Harris, C. E.: "A Deformation-Formulated Micromechanics Model of the Effective Young's Modulus and Strength of Laminated Composites Containing Local Ply Curvature," Composite Materials: Testing and Design (Ninth Volume), ASTM STP 1059, S. P. Garbo, Ed., American Society for Testing and Materials, Philadelphia, 1990, pp. 521-563.

24. Naik, R. A. and Crews, J. H., Jr.: "Micromechanical Analysis of Fiber-Matrix Interface Stresses Under Thermomechanical Loadings," Composite Materials: Testing and Design (Eleventh Volume), ASTM STP 1206, E. T. Camponeschi, Jr., Ed., American Society for Testing and Materials, 1993, pp. 205-219.

25. Ho, H., Tsai, M. Y., Morton, J., and Farley, G. L.: "In-plane Shear Testing of Graphite-woven Fabric Composites, " Experimental Mechanics, March 1994, pp. 4552.

26. Fedro, M. J. and Willden, K.: "Characterization and Manufacture of Braided Composites for Large Commercial Aircraft Structures," " Proceedings of the Second NASA Advanced Composites Technology Conference, NASA CP 3154, Jun. 1992, pp. 387-429.

27. Masters, J. E. and Minguet, P. J.: "Effect of Preform Architecture on Modulus and Strength of 2-D Triaxially Braided Textile Composite Materials", Presented at the ASTM 12th Symposium on Composite Materials: Testing and Design, May 16-17, 1994, Montreal, Canada, American Society for Testing and Materials, Philadelphia.

28. Hercules Carbon Fabric (Style A*193-P) Product Data Sheet, Number 852-2, Hercules, Inc., Magna, Utah, June 1989. 
Table 1.- Yarn and resin properties used in the analysis.

\begin{tabular}{|c|c|c|c|c|c|c|c|c|}
\hline Material & $\mathrm{E}_{11}, \mathrm{GPa}$ & $\begin{array}{c}\mathrm{E}_{22}, \\
\mathrm{GPa}\end{array}$ & $\mathrm{G}_{12}, \mathrm{GPa}$ & $v_{12}$ & $v_{23}$ & $\begin{array}{c}\mathrm{CTE} \alpha_{11}, \\
10-6 /{ }^{\circ} \mathrm{C}\end{array}$ & $\begin{array}{c}\mathrm{CTE} \alpha_{22}, \\
10-6 / \mathrm{O}^{\circ} \mathrm{C}\end{array}$ & $\mathrm{m}$ \\
\hline Yarn [14] & 151.00 & 10.10 & 5.70 & 0.24 & 0.50 & -0.324 & 14.000 & 2.78 \\
\hline Yarn [15] & 144.80 & 11.73 & 5.52 & 0.23 & 0.30 & -0.324 & 14.000 & 2.78 \\
\hline Resin [15] & 3.45 & 3.45 & 1.28 & 0.35 & 0.35 & 40.000 & 40.000 & 2.34 \\
\hline
\end{tabular}

Note: The 1-axis is along the fiber direction, the 2-axis is perpendicular to the fibers but in the plane of the lamina and the 3-axis is in the out-of-plane direction.

Table 2.- Ultimate stress/ strain properties for the impregnated yarns and resin.

\begin{tabular}{|c|c|c|c|c|c|c|c|c|}
\hline Material & $\begin{array}{c}\left(\sigma_{11}\right)_{\text {Ten }} \\
\mathrm{MPa}\end{array}$ & $\begin{array}{c}\left(\sigma_{11}\right)_{\mathrm{Com}} \\
\mathrm{MPa}\end{array}$ & $\left(\varepsilon_{11}\right)_{\mathrm{Ten}}$ & $\left(\varepsilon_{11}\right)_{\mathrm{Com}}$ & $\begin{array}{c}\left(\sigma_{22}\right)_{\mathrm{Ten}} \\
\mathrm{MPa}\end{array}$ & $\begin{array}{c}\left(\sigma_{22}\right)_{\mathrm{Com}} \\
\mathrm{MPa}\end{array}$ & $\begin{array}{c}\left(\sigma_{12}\right) \\
\mathrm{MPa}\end{array}$ & $\begin{array}{c}\left(\sigma_{23}\right) \\
\mathrm{MPa}\end{array}$ \\
\hline Yarns & - & - & 0.014 & 0.010 & 26.0 & 206.0 & 87.5 & 102.4 \\
\hline Resin [18] & 84.9 & 84.9 & - & - & - & - & 98.3 & 98.3 \\
\hline
\end{tabular}

Note: The 1-axis is along the fiber direction, the 2-axis is perpendicular to the fibers but in the plane of the lamina and the 3-axis is in the out-of-plane direction. 
Table 3.- Comparison of results for plain weave composites.

\begin{tabular}{|c|c|c|c|c|c|c|}
\hline Source & $\begin{array}{c}\text { Yarn size } \\
(\mathrm{k})\end{array}$ & $\begin{array}{c}\text { Yam spacing } \\
(\mathrm{mm})\end{array}$ & $\begin{array}{c}\mathrm{V}_{\mathrm{f}} \\
(\%)\end{array}$ & Loading & $\begin{array}{c}\text { Strength } \\
(\mathrm{MPa})\end{array}$ & $\begin{array}{c}\text { TEXCAD } \\
\text { Prediction (MPa) }\end{array}$ \\
\hline Ref. 14 & 3 & 2.22 & 60.0 & Tension & 753 & 780 \\
\hline & & & & Compression & - & 660 \\
\hline & & & & Shear & 103 & 91 \\
\hline
\end{tabular}

\begin{tabular}{|c|c|c|c|c|c|c|}
\hline Ref. 25 & 12 & 3.33 & 52.2 & Tension & - & 600 \\
\hline & & & & Compression & - & 540 \\
\hline & & & & Shear & 100 & 94 \\
\hline
\end{tabular}

\begin{tabular}{|c|c|c|c|c|c|c|}
\hline Ref. 28 & 3 & 2.22 & 62.0 & Tension & 690 & 720 \\
\hline & & & & Compression & 656 & 640 \\
\hline & & & & Shear & - & 91 \\
\hline
\end{tabular}

Table 4.- Input parameters for $2 \times 2,2-D$ triaxial braided composites [12].

\begin{tabular}{|c|c|c|c|c|c|}
\hline $\begin{array}{c}\text { 2-D triaxial } \\
\text { braid }\end{array}$ & $\begin{array}{c}\text { Braid angle, } \\
\text { degrees }\end{array}$ & $\begin{array}{c}\text { Braider yarn } \\
\text { size, } \mathbf{k}\end{array}$ & $\begin{array}{c}\text { Axial yarn } \\
\text { size, } \mathbf{k}\end{array}$ & $\begin{array}{c}\text { Axial yarn } \\
\text { spacing, mm }\end{array}$ & $\begin{array}{c}\text { Overall fiber } \\
\text { volume } \\
\text { fraction, } \%\end{array}$ \\
\hline A1 & 63.0 & 12 & 24 & 6.096 & 54.0 \\
\hline B1 & 66.5 & 6 & 18 & 5.320 & 52.3 \\
\hline B2 & 70.0 & 6 & 18 & 5.820 & 48.9 \\
\hline
\end{tabular}


Table 5.- Comparison of results for 2x2, 2-D triaxial braided composites.

\begin{tabular}{|c|lr|rr|rr|}
\hline \multirow{2}{*}{ Architecture } & \multicolumn{2}{|c|}{$\begin{array}{c}\text { Longitudinal tension } \\
\text { strength (MPa) }\end{array}$} & \multicolumn{2}{c|}{$\begin{array}{c}\text { Transverse tension } \\
\text { strength (MPa) }\end{array}$} & \multicolumn{2}{c|}{$\begin{array}{c}\text { Longitudinal } \\
\text { compression strength } \\
\text { (MPa) }\end{array}$} \\
& Test [12] & TEXCAD & Test [12] & TEXCAD & Test [26] & TEXCAD \\
\hline A1 & $432 \pm 21$ & 504 & $249 \pm 14$ & 350 & 308 & 384 \\
\hline B1 & $556 \pm 10$ & 546 & $289 \pm 17$ & 340 & 508 & 429 \\
\hline B2 & $394 \pm 11$ & 507 & $310 \pm 35$ & 400 & 390 & 370 \\
\hline
\end{tabular}



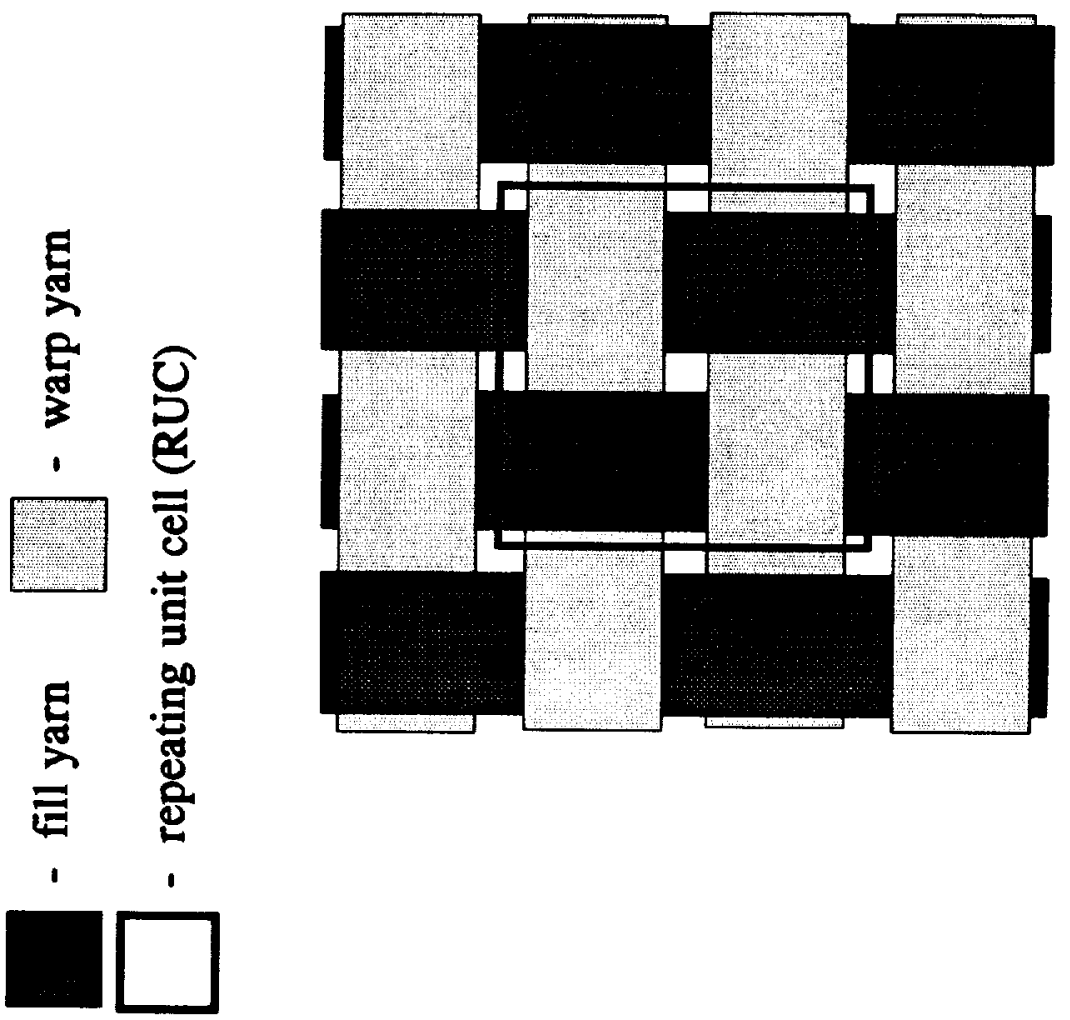

号 


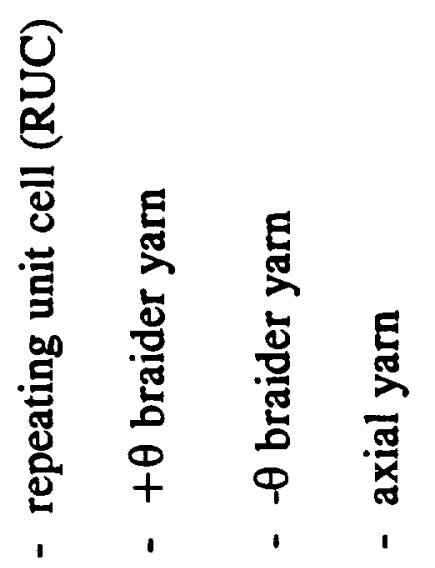

总

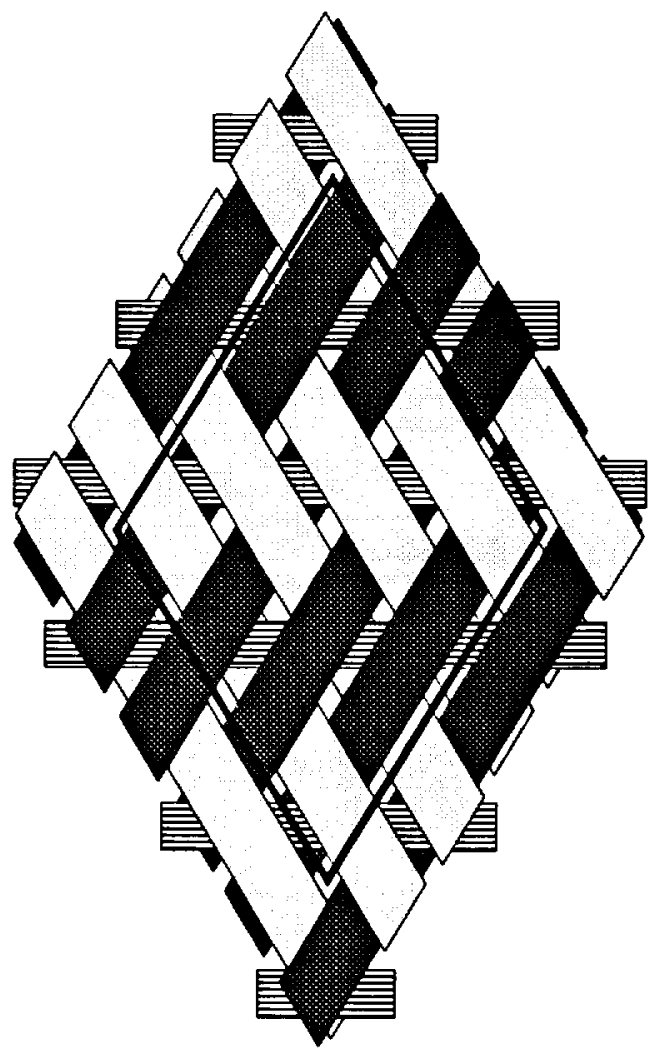

a 


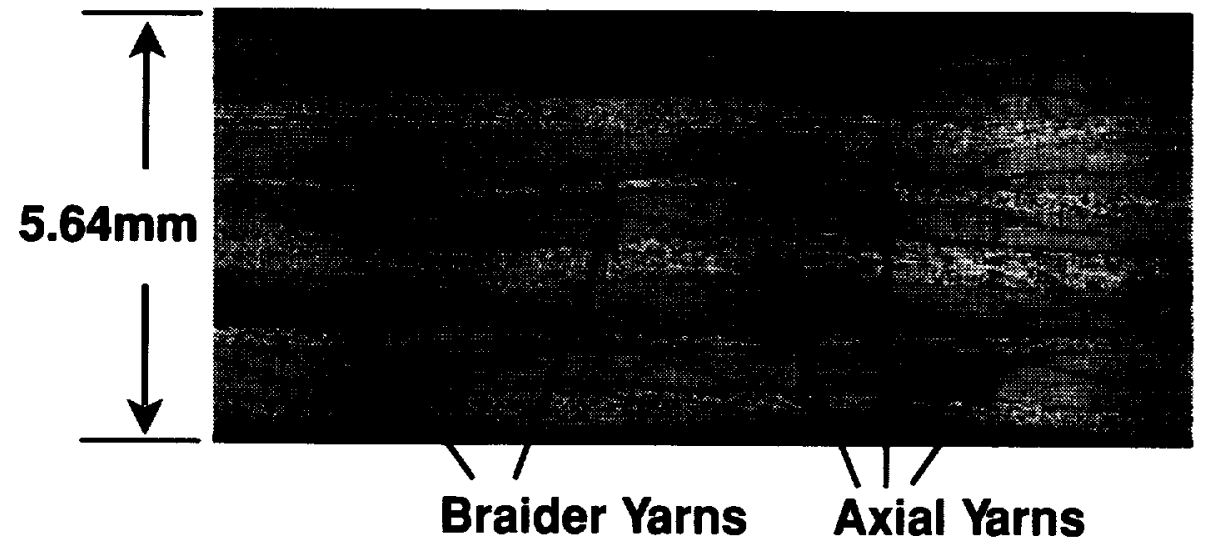

(a) Longitudinal section along axial yarns

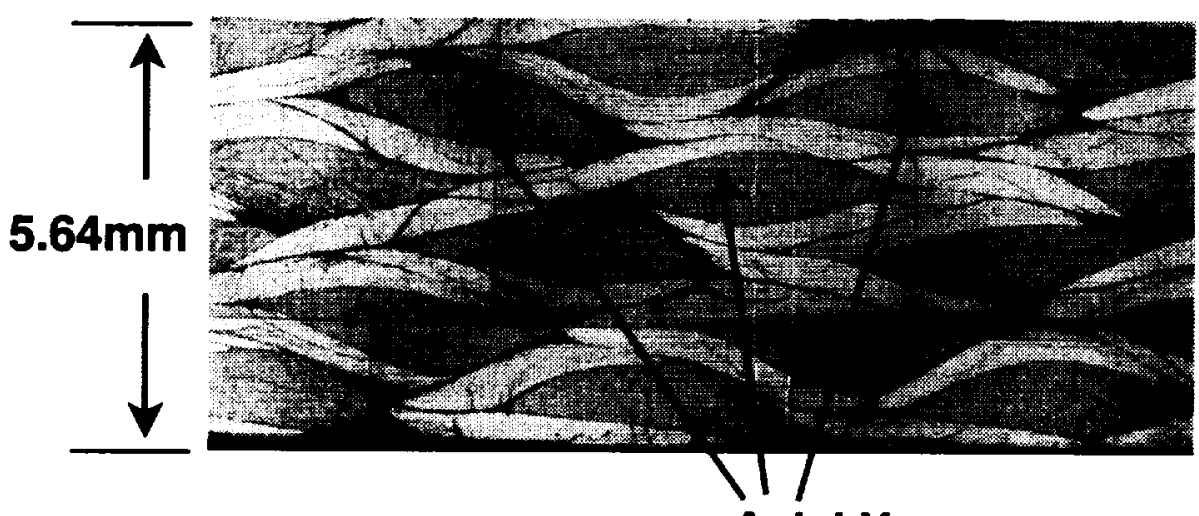

\section{Axial Yarns}

\section{(b) Transverse section}

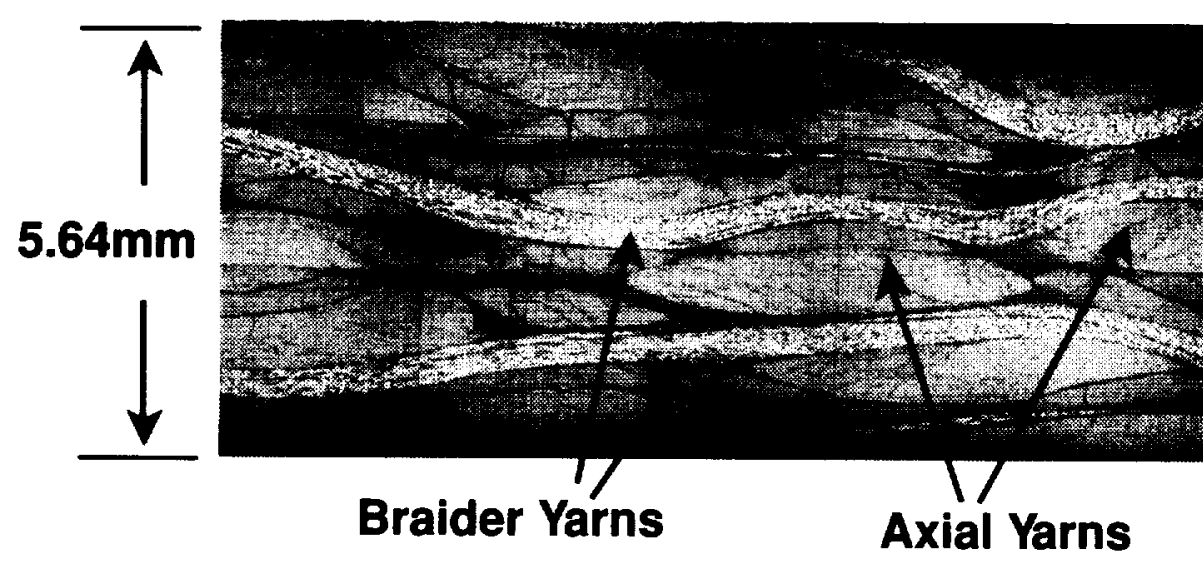

(c) Section along braider yarns

Fig. 3 - Typical cross-sectional micrographs of a $2 \times 2,2-D$ triaxial braided composite. 


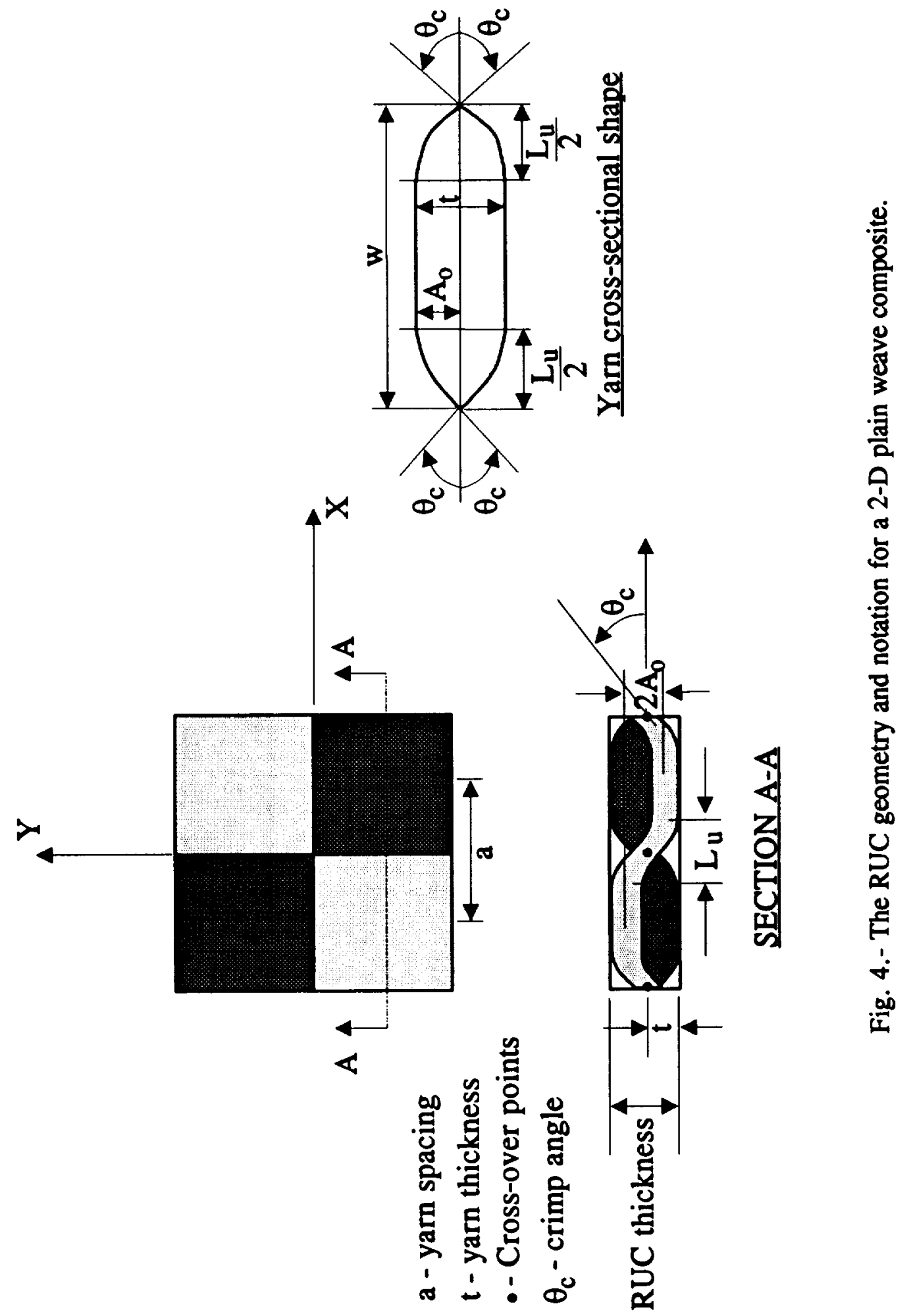




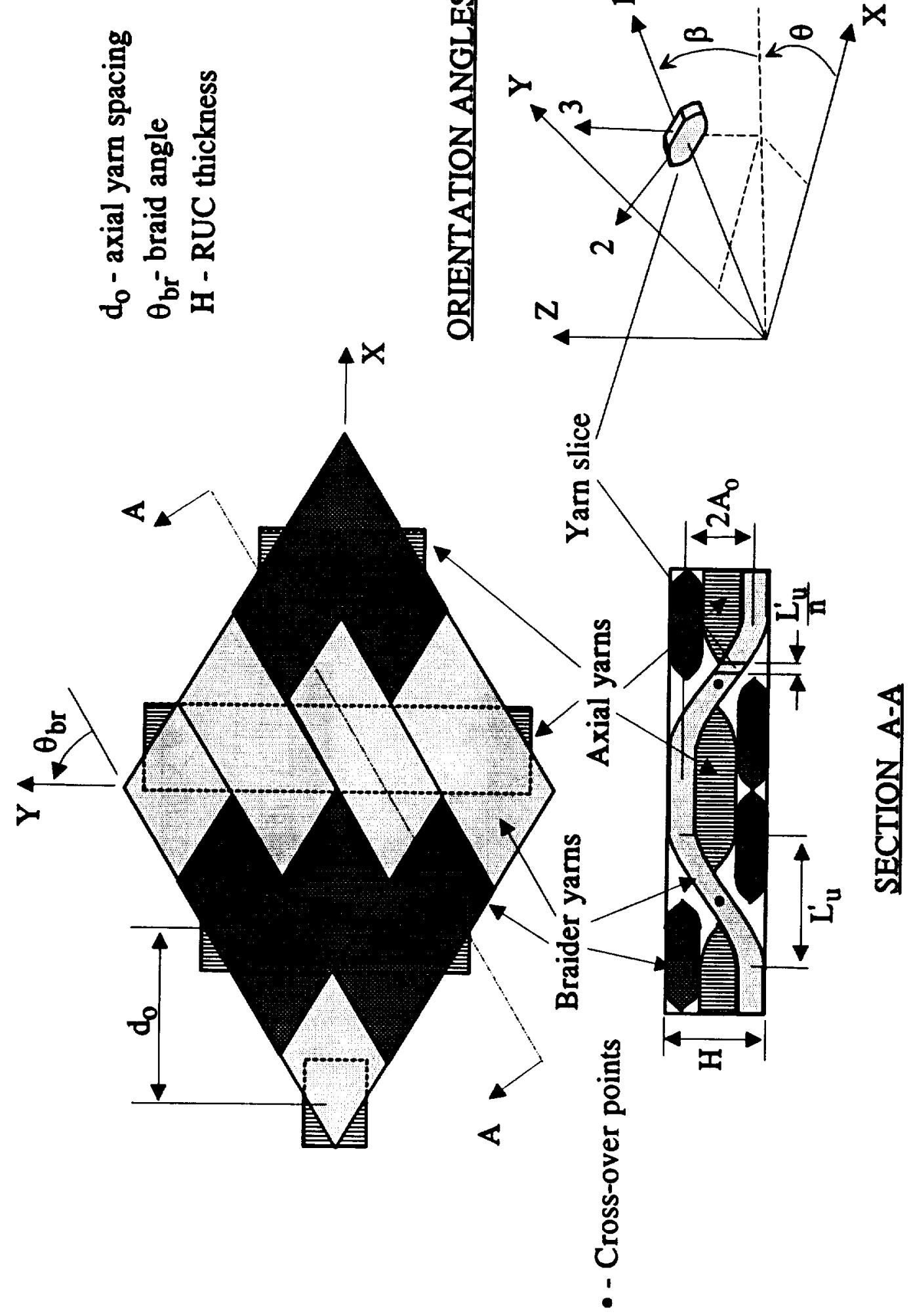

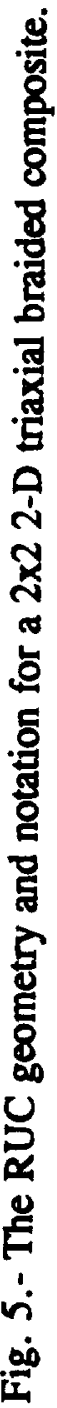




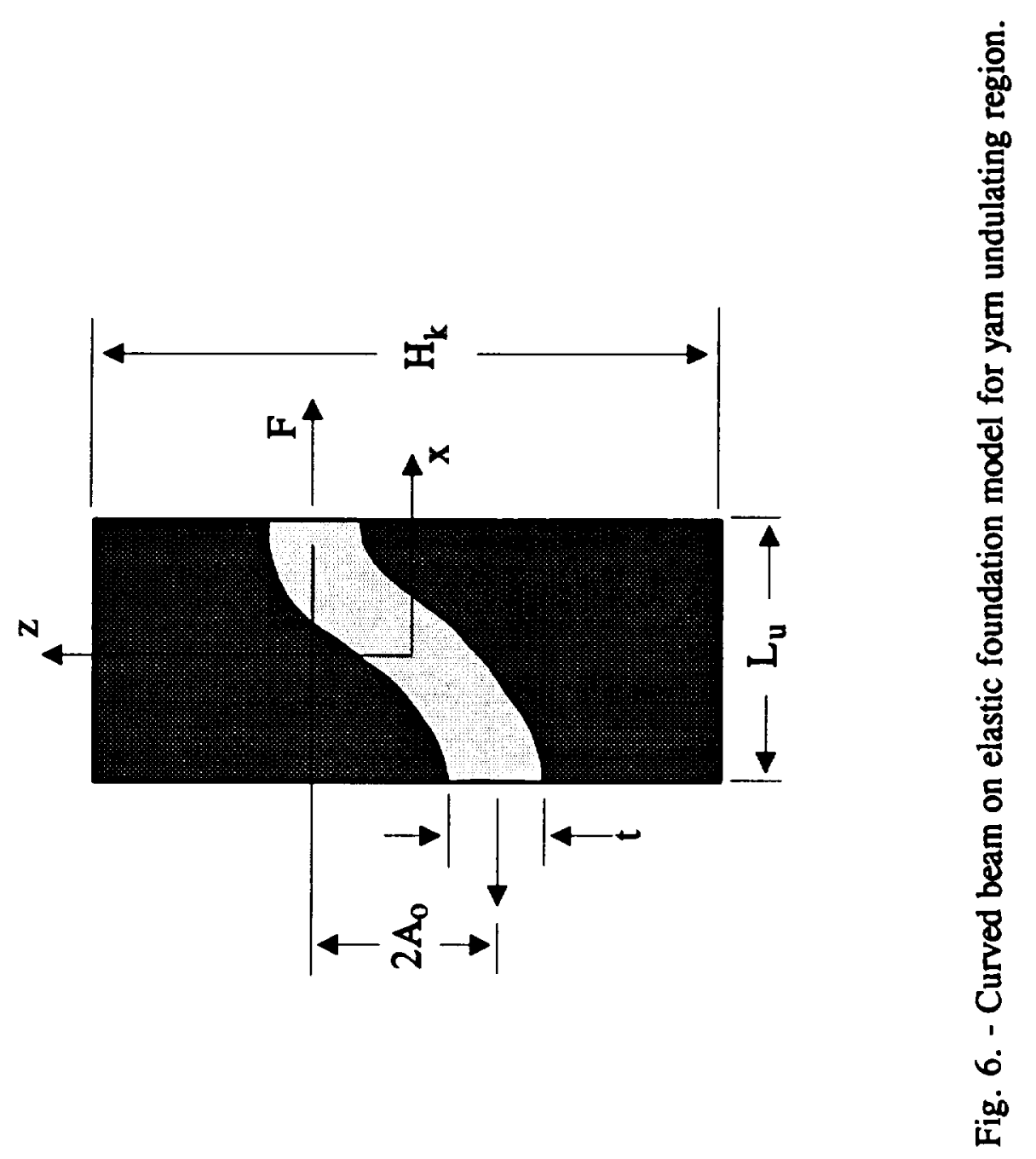




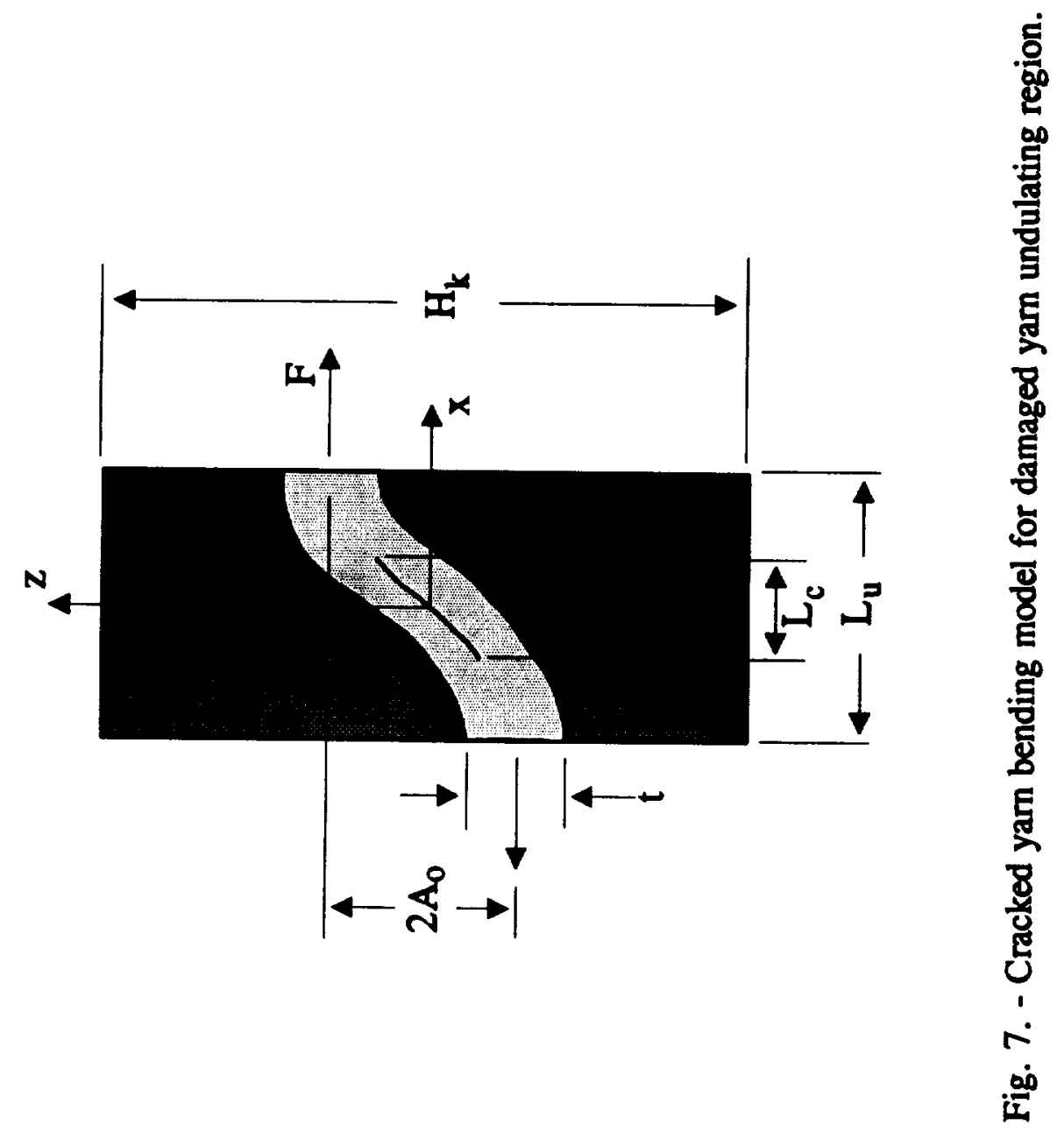




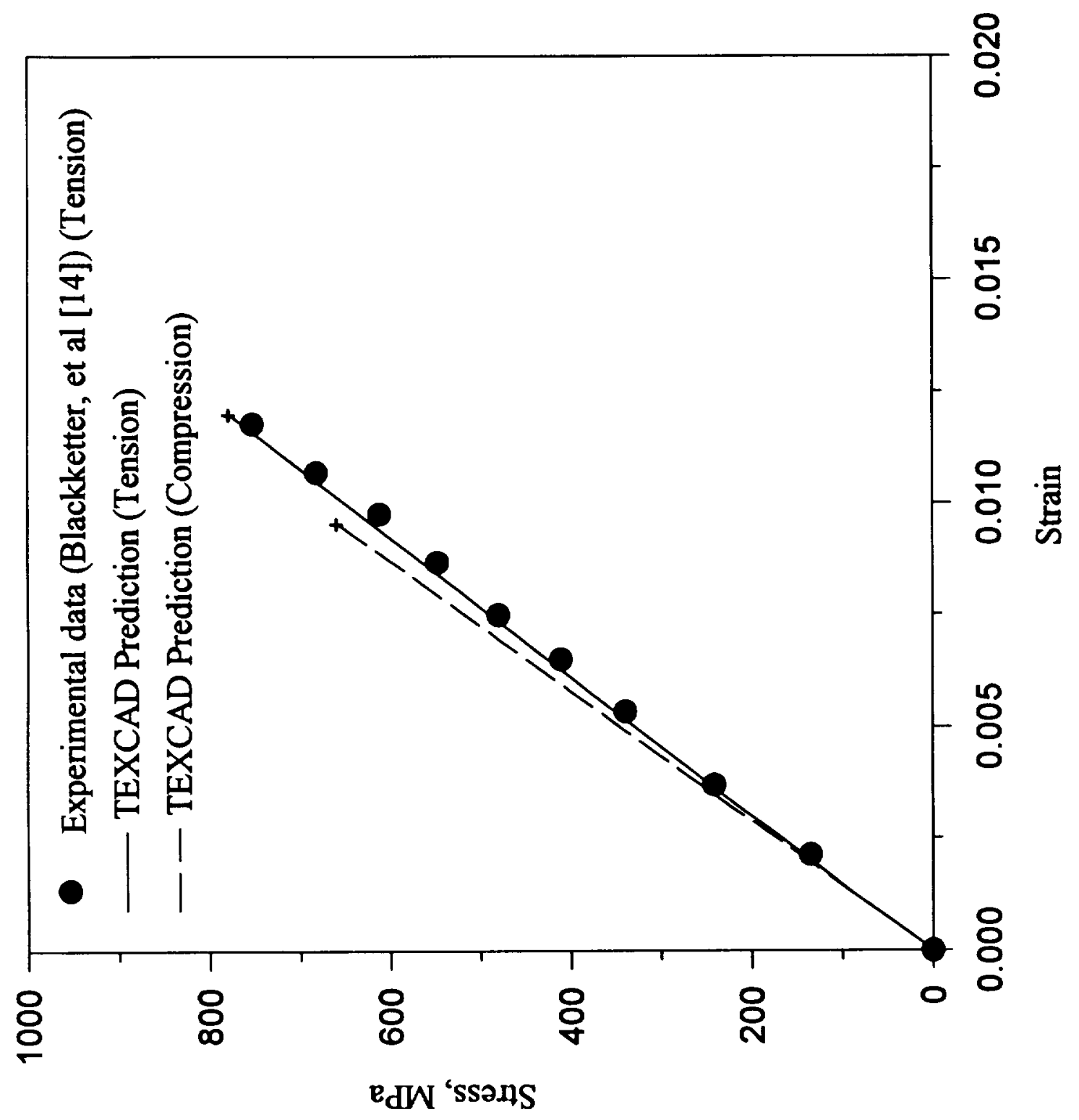

ญ. 


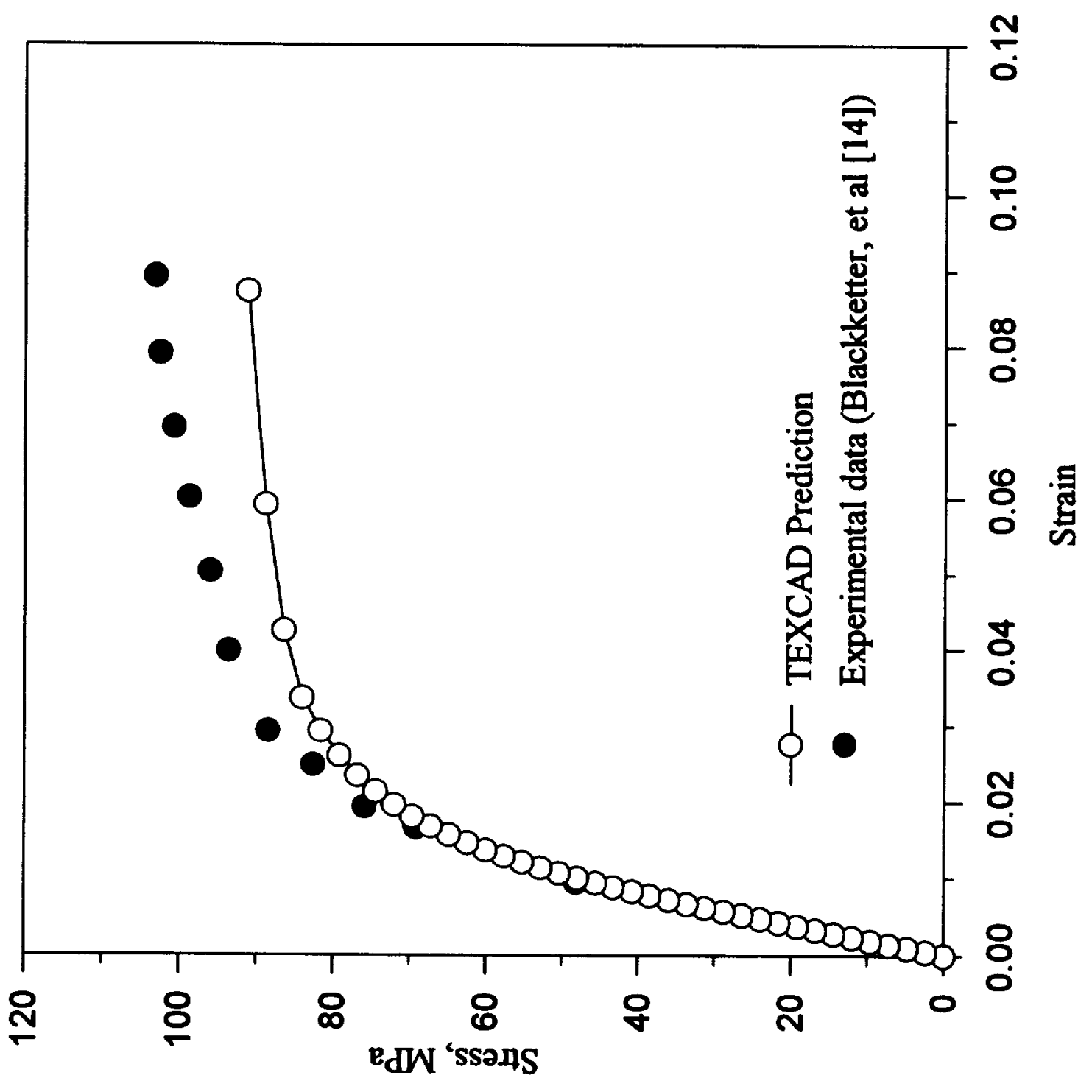

हิ 


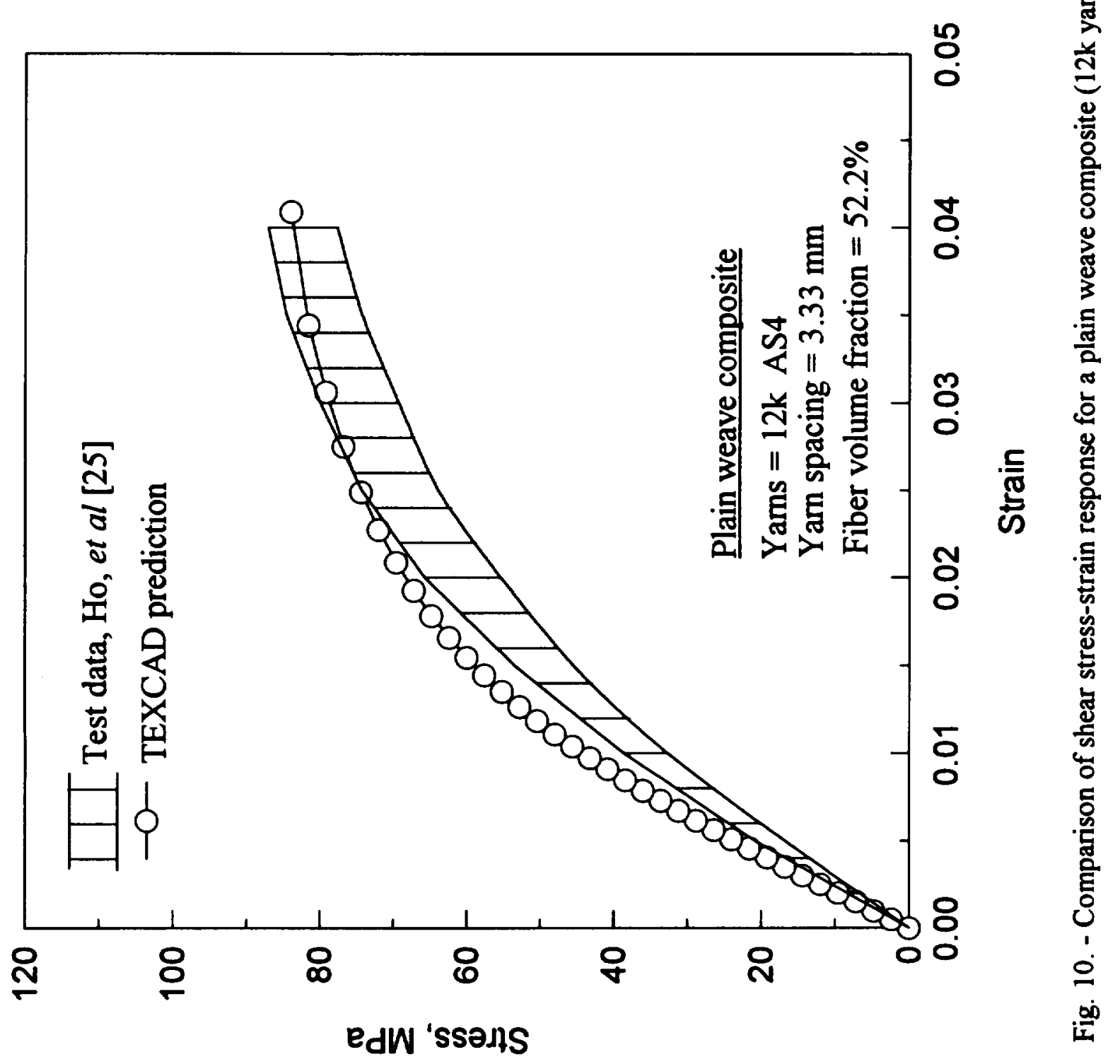




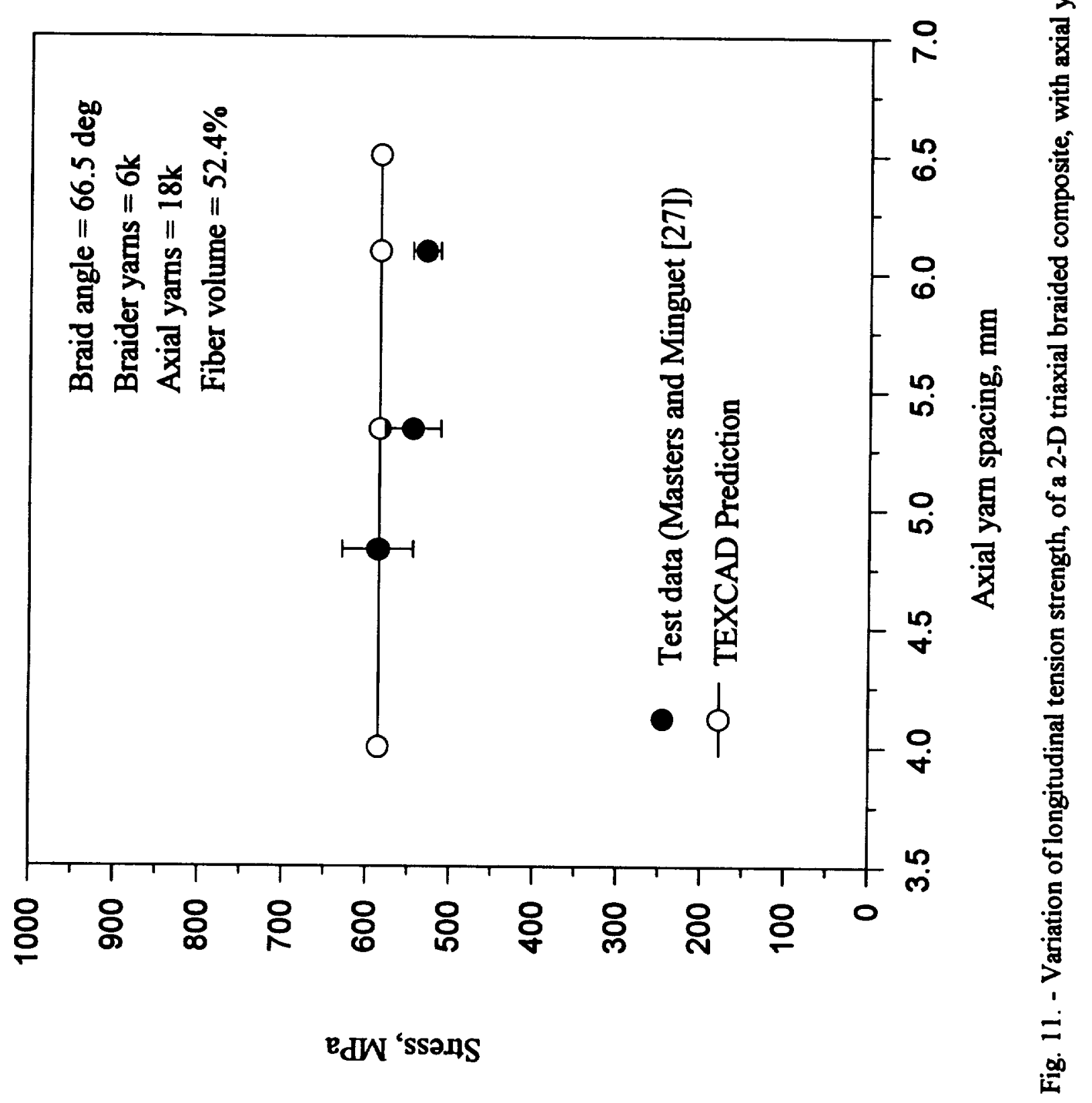




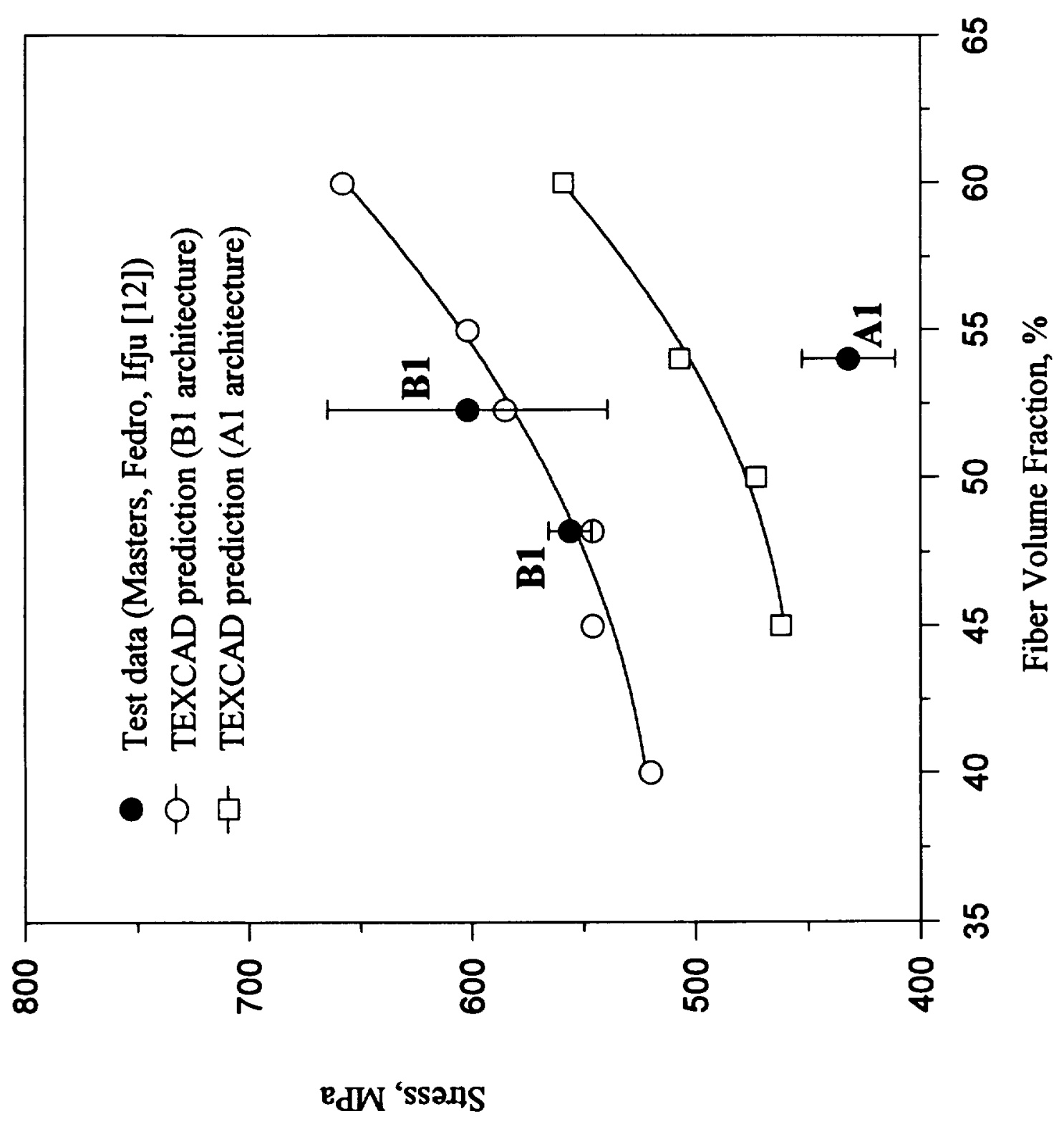

얼 


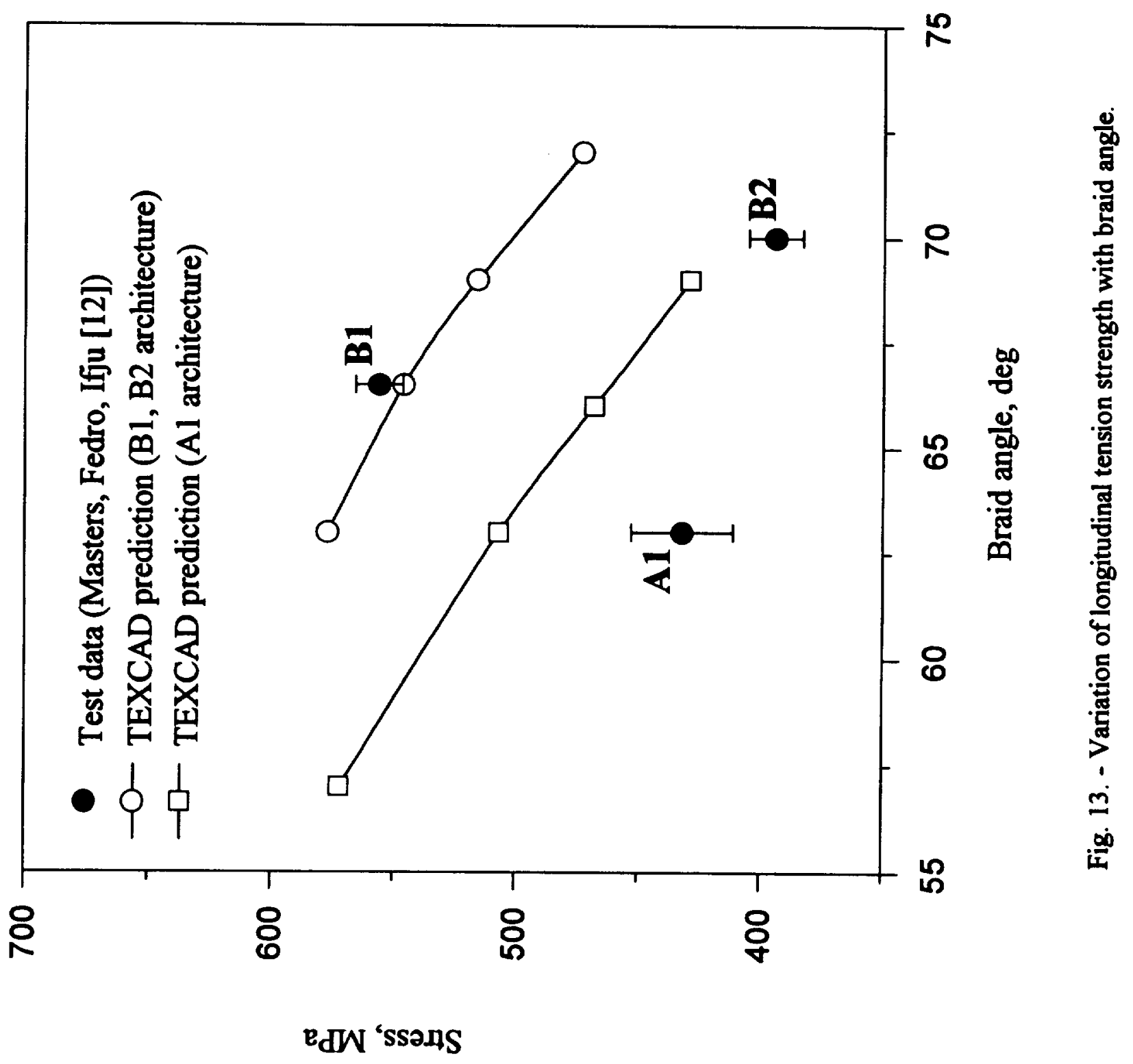




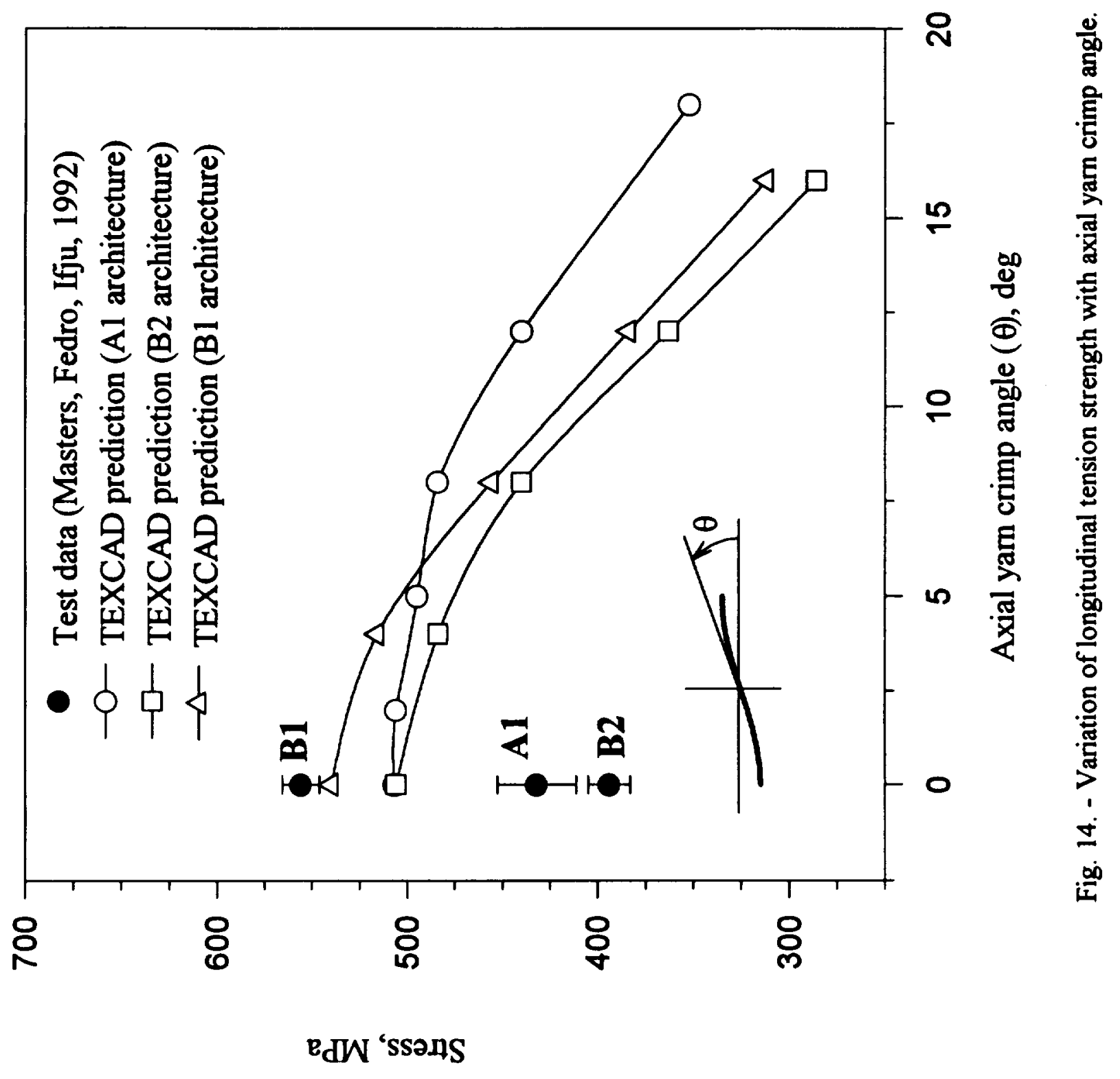




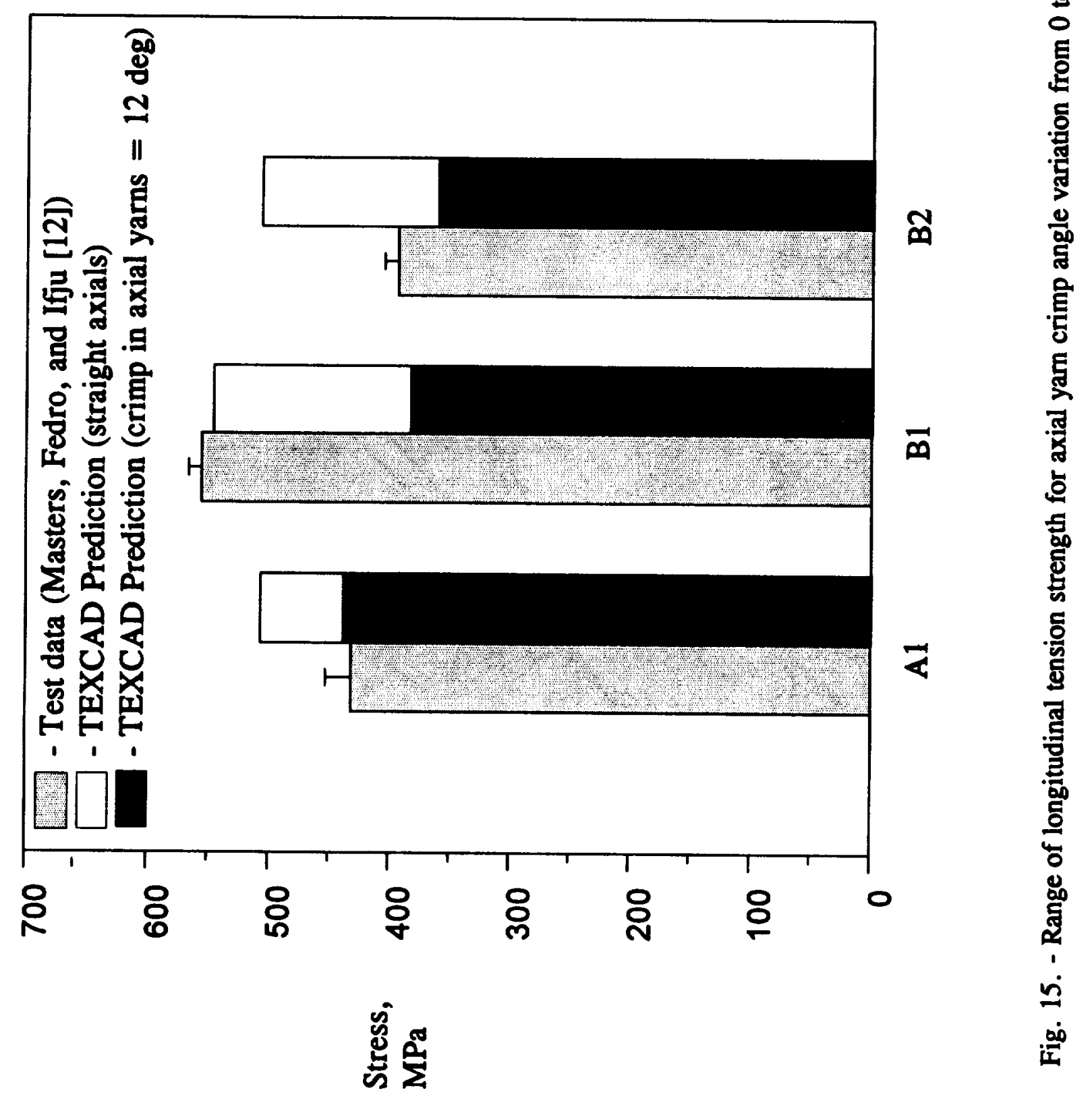





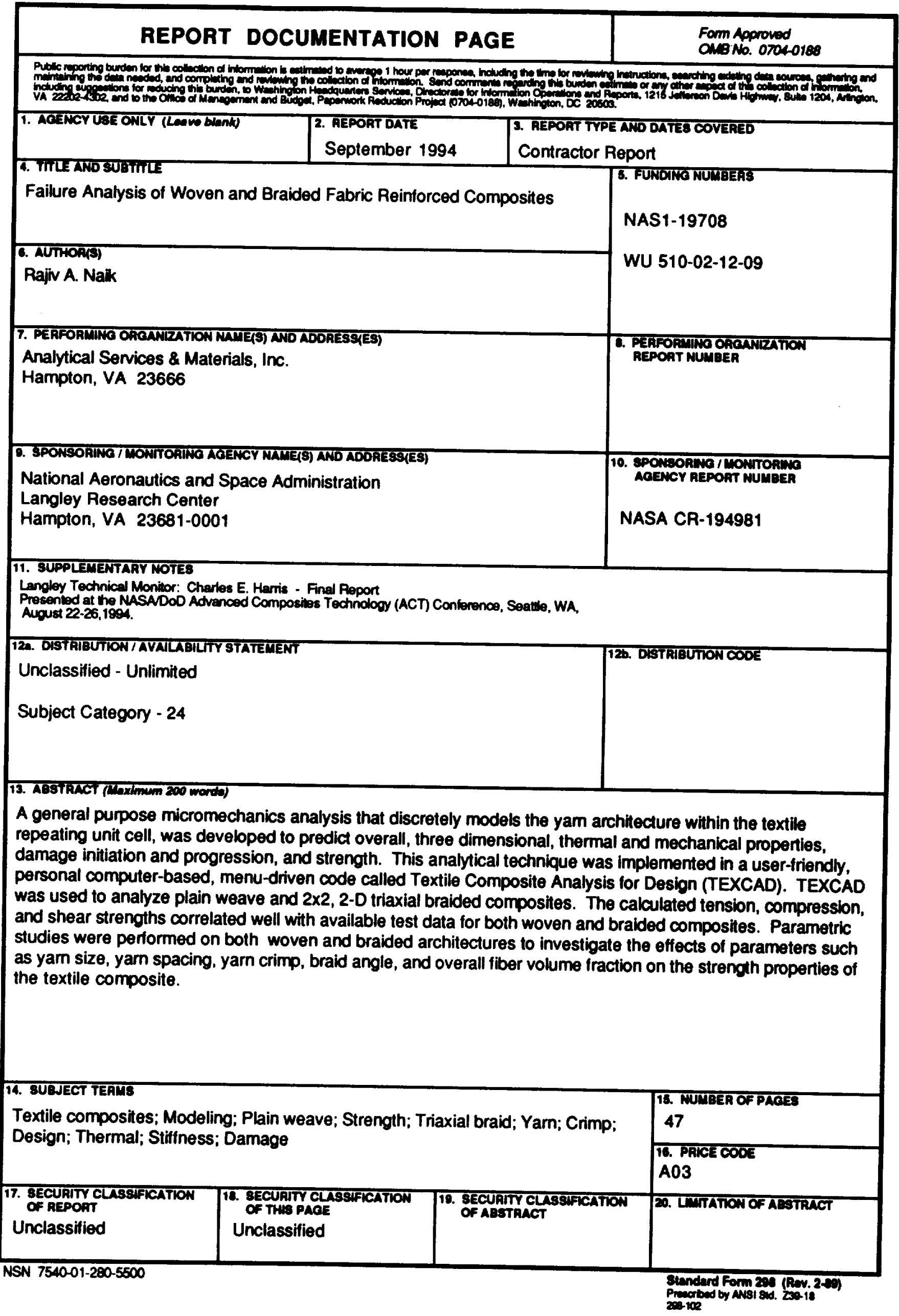

